Universidad de Lima

Facultad de Comunicación

Carrera de Comunicación

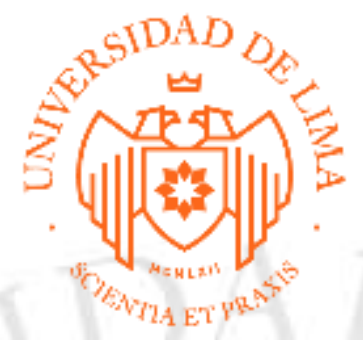

\title{
RELANZAMIENTO DE LA ESCUELA DE COMUNICACIONES DE LA UCSUR
}

Trabajo de Suficiencia Profesional para optar el Título Profesional de Licenciado en

\author{
Comunicación
}

\section{Maritza Enciso Zegarra}

Código 872226

\section{Asesor}

Prof. Nestor Martos Castañeda

$$
\text { Lima - Perú }
$$

Setiembre 2019 


\section{RELANZAMIENTO DE LA ESCUELA DE COMUNICACIONES UCSUR}




\section{ÍNDICE}

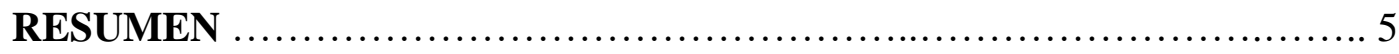

INTRODUCCIÓN ..................................................... 6

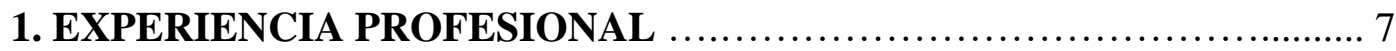

1.a Resumen detallado de experiencia profesional ........................ 7

2. COMPETENCIAS PROFESIONALES .............................. 12

2.a Reflexión inicial ................................................. 12

2.b Antecedentes .................................................. 13

2.c Objetivos .............................................. 14

3. DESCRIPCION DEL CASO ..................................... 14

3.1. Rediseño y creación de la propuesta de valor ............................. 15

3.1.i. Antecedentes ................................................. 15

3.1.ii Incremento de la atractividad ................................. 15

3.1.a. Creación de las 4 especialidades ................................ 18

3.1.b. Creación de los Laboratorios de Desarrollo Profesional (LDP) ...... 19

3.1.b.1. Comunicación de influencia y motivación................... 20

3.1.c. Proyectos .................................................. 23

3.1.d. Concursos .................................................... 23

3.2. Experiencia-Cliente y Cultura .......................................... 25

3.2.a. Estrategia de Fidelización. Procesos y construcción de KPIs .......... 25

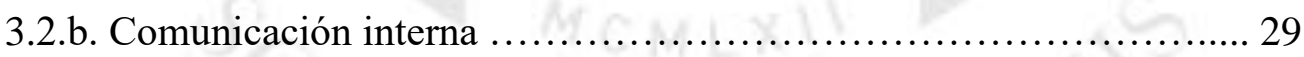

3.2.b.1. Creación del discurso ................................... 30

3.2.b.2. Sistema de Reconocimiento de logros .................... 32

3.2.c. Aseguramiento del nivel de satisfacción ......................... 35

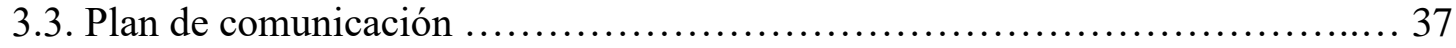

3.3.a. Posicionamiento de ideas fuerza ................................. 37

3.3.a.1 Empleabilidad ...................................... 37

3.3.a.2 Vivir la carea desde la universidad ........................ 38

3.3.a.3 Contacto con la industria ............................... 38

3.3.b Creación de las plataformas de comunicación de la escuela ........... 40

3.3.b.1 Canal de TV. Científica TV ............................ 41 
3.3.b.2 Radio online y ondemand. Cientifica Radio 41

3.3.b.3 Revista impresa. Científica Magazine 41

3.3.b.4 Periódico Digital. Científica Digital News 42

3.3.b.5 Blog de Comunicación Organizacional. Científica Consultiva .... 42

3.3.b.6 Agencia de Publicidad. Científica Creativa .................... 42

3.3.c. Comunicación externa ............................................. 43

3.3.c.1 Relanzamiento. Escuela de comunicaciones y LDP .............. 44

3.3.c.2 Creación del perfil Público oficial de la escuela ................... 48

4. Reflexiones profesionales ............................................... 50

Bibliografía ................................................................ 51

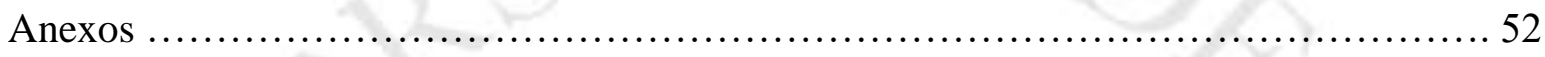




\section{RESUMEN}

El presente trabajo aborda la gestión de las comunicaciones de un caso específico de negocio, desde la perspectiva de producto (propuesta de valor) en el sector educación y desde la perspectiva de Dircom, analizando y definiendo la estrategia de comunicación para el negocio. Sin embargo, el reto completo se puede entender considerando que los objetivos que asumí con el cargo de Directora de la Escuela de Comunicaciones de la UcSur fueron el desarrollo del negocio, el crecimiento de las ventas, el incremento de ingresantes, la reducción de la deserción estudiantil, el incremento de la satisfaccion de usuarios, incremento de la recomendación; traducidos en los resultados anuales del negocio.

Describo en este trabajo, las áreas que atendí a través del diseño, dirección e implementación de la estrategia de comunicación, pero hago énfasis en que como Directora de negocio, el éxito fue producto de gestionar simultáneamente, los recursos humanos, los resultados financieros, el cumplimiento de la normativa del sector, la optimización y tranformación de procesos, la innovación en los servicios, y todo ello posible únicamente a través de un liderazgo disruptivo y convocante. 


\section{INTRODUCCIÓN}

\section{Descripción del perfil educativo, académico y campo laboral}

Orienté mi formación y quehacer profesional hacia la estrategia empresarial, utilizando a las comunicaciones como plataforma para alinear a clientes y stakeholders con los objetivos corporativos de crecimiento, competitividad, rentabilidad, excelencia y posicionamiento. He trabajado en los sectores IT y Educación, ayudando a las empresas a desarrollar sus mercados, analizando, diagnosticando y formulando soluciones en el ámbito de la estrategia competitiva y comercial, creando propuestas de valor basadas en el profundo conocimiento del cliente, sus preferencias, insights, sus formas de interactuar, decidir y comprar; he gestionado y formando equipos, planes comerciales y marketing multiplataformas, BTL, ATL y digitales, orientándome a lograr resultados medibles bajo la lupa de indicadores y métricas para guiar y dinamizar a mis equipos de trabajo, articulando todo simultáneamente, tanto lo estratégico como lo operativo y utilizando a la comunicación como hilo conductor, conector, transmisor, movilizador y amalgama de la dinámica empresarial.

Con este objetivo en mente, definí mi orientación profesional hacia la Comunicación Organizacional, ampliando mis áreas de conocimiento y campo de acción con diferentes especializaciones a lo largo de mi vida profesional. He complementado mi formación profesional con las siguientes especializaciones y grados:

MBA por la Universidad de Quebec-Montreal

Diploma de Especialización en Marketing, por Esan

Diplomada PAD - Dirección Comercial por la Universidad de Piura

Diploma de post grado Master en Innovación Corporativa por la Universidad Stanford

Diploma en Responsabilidad social - Universidad Científica del Perú

Diploma en Planeamiento Estratégico por Esan

Analítica de Datos y BI - Universidad del Pacífico 


\section{EXPERIENCIA PROFESIONAL}

Mi trayectoria profesional de más de 10 años, ha cubierto de forma complementaria diferentes áreas estratégicas y operativas del ejercicio de las comunicaciones, que resumo a continuación:

1.a. Resumen detallado de experiencia profesional en el ejercicio de las comunicaciones

\section{7- 2018. DIRECTORA GENERAL - CORPORACION DE COLEGIOS Y FRANQUICIAS}

Dirección global de la estrategia de negocio a nivel nacional (17 sedes en lima, provincias y red de franquicias), liderando un equipo de +1000 colaboradores (comercial, marketing, operaciones, producto)

Análisis de mercado y diagnóstico del negocio, definiendo la estrategia corporativa, planes operativos y acciones tácticas para fortalecer la imagen de marca, la propuesta de valor, el posicionamiento de sus servicios, a través de un plan integral comercial, de marketing, de cambio cultural interno y comunicación externa, sincronizados hacia los objetivos de ventas, rentabilidad y reconocimiento social de la marca.

Reenfoque de la estrategia del negocio hacia el Customer-Experience, implementando metodologías agiles y SCRUM para la implementación de mejoras en los procesos de delivery de servicio, con el objetivo de reducir la deserción de estudiantes.

Dirección de la estrategia de branding y awareness de marca, orientadas a la generación de demanda, desarrollando campañas BTL, activaciones a nivel nacional, campañas y eventos de movilización y responsabilidad social, logrando incrementando la imagen de marca, el tráfico en sedes y alcanzar el cumplimiento de los objetivos de ventas

Relanzamiento de la propuesta de valor de la marca, analizando, identificando e incorporando nuevos insights de alta valoración en el mercado, cambiando metodologías académicas de uso común en la industria por nuevos modelos propios, "brandeadas" con el sello de la marca, buscando un posicionamiento diferenciado en el mercado y relevancia en la industria, transformando procesos ordinarios de comunicación masiva y operativa con los clientes, con la creación de formatos y espacios de dialogo, de confraternización, de participación y aporte, permitiendo identificar las bases la personalización del servicio, y establecer kpis y métricas de medición de la efectividad de esas nuevas prácticas, asociadas al objetivo matriz de incrementar la capacidad competitiva del negocio a través de la excelencia de la Experiencia-cliente.

Relanzamiento de la imagen gráfica de la marca (material publicitario), creando nuevos discursos, generando contenidos para redes sociales y ATL (prensa, tv y radio). Planificación y ejecución del presupuesto publicitario.

Incremento de las capas de valor del producto base, desarrollando una estrategia de Branding asociadas a proyectos de responsabilidad social y emprendimiento estudiantil. 
Transformación digital de los procesos de ventas implementando matrices de automatización de datos y dashboards para el seguimiento, comprobación y medición en tiempo real de la efectividad de campañas y activaciones, acelerando la toma de decisiones y optimizando tiempo y recursos de los colaboradores.

\section{$2014-2017$}

\section{Universidad Científica del Sur}

\section{DIRECTORA DE LA ESCUELA DE COMUNICACIONES Y PUBLICIDAD}

Planificación de la estrategia, planes y acciones alineados a los objetivos del negocio de incremento del número de ingresantes, desarrollo del posicionamiento y atractividad de la escuela, mejora de la imagen y reputación de la marca, incremento de la demanda de los servicios académicos, mejora de la satisfacción de estudiantes para reducir la deserción y desarrollo de mercado a través del lanzamiento de nuevos cursos y productos académicos para post grado (Maestría, especializaciones) y cursos libres para profesionales, que permitan incrementar los ingresos del negocio y la percepción de valor de la marca en los grupos de interés internos (endomarketing) y externos (branding y reconocimiento social).

Incremento de la facturación del negocio en $280 \%$, en 3 años, construyendo una propuesta de valor disruptiva y un discurso comercial de relevancia en el mercado, identificando insights y variables decisoras de compra del público objetivo actual y potencial, incorporando nuevas capas de valor al producto base, evaluando y redefiniendo la estructura de colaboradores con indicadores asociados al logro de los objetivos del negocio, ejecutando un plan de cambio de mindset, ejecutando el plan de comunicación interna para alinear a los equipos y un plan de marketing de generación de contenidos, específicos de la escuela y complementarios a la publicidad genérica ejecutada por el área de marketing, todo sincronizado de forma simultánea y controlando los logros a través de KPIs, cronogramas y planes de trabajo.

Creación de 4 lineas de especialización comunicacional (Periodismo, Publicidad, Comunicación corporativa y Medios audiovisuales), actualización del plan de estudios, reorientando cada especialidad hacia el logro de entregables complementarios y asociados entre los cursos de la especialidad, válidos para la construcción de contenidos "comercializables" por el área de marketing.

Creación de 4 laboratorios profesionales (1 por cada línea de especialización), Científica TV, Científica Radio, Científica News (periódico online), Científica Magazine (revista impresa), Blog Científica Consultiva, orientando a la carrera a la práctica profesional, repotenciando el producto académico e incrementando la capacidad competitiva de la escuela y la satisfacción de los estudiantes, medida en el crecimiento de postulaciones, y reducción de la deserción. Incorporación de los laboratorios como parte de la formación transversal de los estudiantes, independientemente de la especialidad escogida,

Reducción de la deserción de 35\% a 3\% anual, rediseñando la propuesta de valor, los servicios complementarios, creando estructuras de soporte a los servicios, creando canales de comunicación con los estudiantes, identificando y resolviendo problemáticas a nivel de calidad y experiencia-cliente, estableciendo planes de trabajo 
y cronogramas semestrales, creando e implementando KPIs de satisfacción de clientes en la medición de performance de todos los colaboradores.

Dirección de la creación y difusión de contenidos de generación de imagen y "evidencia de éxito" de la escuela, como parte del ejercicio profesional de los estudiantes, logrando parrillas de hasta 6 programas por semana (TV), programación online y on demand diaria para la radio, lanzamiento semestral de científica Magazine, Actualización diaria de Científica News (periódico online), con la participación directa de estudiantes desde el 1er ciclo de la escuela.

Creación, Dirección y lanzamiento de la Revista de la Escuela de comunicaciones "Científica News", con un tirale de 2000 ejemplares semestrales, producido íntegramente por estudiantes de tods los ciclos de la escuela y el soporte de profesores lideres encargados en cada especialidad.

Creación y Dirección de la Agencia de publicidad Universitaria "Científica Creativa", desarrollando campañas de promoción de la marca, campañas para clientes externos y campañas internas de la escuela de comunicaciones dirigidas a la comunidad universitaria.

- Creación del área de Producción Audiovisual de la escuela, liderando el rodaje de 2 cortometrajes "Por siempre Mia" y "Reminiscencia" este último finalista del concurso de cortometrajes 2015.

Desarrollo de campañas de responsabilidad social asociadas al posicionamiento ambiental de la marca, movilizando municipalidades, instituciones privadas y ongs, incrementando el awareness y la fidelización de marca, en campañas realizadas por estudiantes de la escuela.

\section{DIRECTORA DE EXTENSIÓN UNIVERSITARIA Y ALIANZAS}

Construir y Desarrollar el Clima y la Identidad de la universidad "científica", dirigiendo los servicios de Vida Universitaria de la universidad, integrando toda Comunidad universitaria y logrando que se sientan orgullosos de ser parte de la científica. Asimismo, proyectar social y empresarialmente una imagen prestigiosa de fuerte posicionamiento que ayude a incrementar el valor de la marca y la percepción del valor de sus servicios y ejecutando proyectos vinculantes con instituciones públicas y privadas, logrando en conjunto reducir las las tasas de deserción estudiantes e incrementar la recomendación de la marca.

Las unidades dirigidas dentro de la Dirección de Extensión universitarias son:

Centro Cultural

Centro de Promoción y desarrollo del deporte

Centro de empleabilidad y desarrollo de carrera

- Unidad de Responsabilidad social universitaria

\section{$1997-1999$}

\section{AFP Nueva Vida (hoy en fusión con Prima AFP)}

\section{JEFE DE TELEMARKETING}

Jefatura perteneciente al Area de Servicio al Cliente, Dirección del área de servicio al cliente inbound y outbound (15 ejecutivos comerciales), responsable de la elaboración 
de campañas de comunicación de "fidelización", "información", "retención y prevención", "promociones", etc y coordinación de la estrategia de comunicación y de marketing para el afiliado en función los resultados de las campañas ejecutadas.

\section{$1996-1997$}

\section{Molitalia}

\section{JEFE DE PRODUCTO}

A cargo del plan de marketing de la línea de negocio "Fideos Molitalia", dando soporte al área comercial para asegurar los objetivos de venta y posicionamiento de marca. Las principales responsabilidades de mi cargo fueron:

- Responsable del análisis de estudios de mercado para conocer la posición de la marca frente a competencia, identificando oportunidades de incremento en la participación de mercado en segmentos determinados, variaciones en las preferencias y demanda de los consumidores, lanzamientos o promociones ejecutadas por los competidores, ingreso o salida de marcas, variedades de fideo, cambios en el precio en el mercado, presencia o ausencia de las diferentes marcas en los canales de distribución tradicionales y modernos.

- Análisis y propuesta de desarrollo de productos, variedades y campañas, estableciendo planes de promoción y fidelización para clientes y usuarios finales, organizando y dirigiendo planes promocionales BTL en canal tradicional y canal moderno, concursos y eventos de generación de awareness de marca.

- Responsable del plan publicitario de la marca en coordinación con la agencia de publicidad, participando en el análisis de los resultados de las diferentes campañas, participando en focus group y paneles de consumidores y clientes, participando en la toma de decisiones para la elaboración de piezas publicitarias y promocionales (radio, tv, paneles, afiches, etc).

- Identificación de nichos no atendidos en el mercado y evaluación (focus, paneles, testeos), para el lanzamiento de nuevas variedades o marcas, bajo la construcción de un nuevo mix de marketing. En este periodo participa en el desarrollo y lanzamiento éxitoso de la marca de fideos "Marcopolo" orientado a un segmento de mercado emergente, "C"," $D$ " y no identificado con el posicionamiento extranjero de la marca "De Italia".

\section{$1993-1996$}

\section{Telematic}

\section{JEFE DE MARKETING}

Responsable del plan de marketing y plan de venta de servicios de capacitación en ofimática, lenguajes de programación, infraestructura de redes, etc. para segmentos corporativos y masivos. Las principales funciones de mi rol fueron:

- Análisis de los resultados de las campañas de promoción (prensa y radio) medidos a través de la generación de demanda via telefónica y via presencial en el punto de venta, definiendo el mantenimiento o desarrollo de nuevas campañas en coordinación con la agencia de publicidad.

Aprobación de las campañas publicitarias, redacción de notas de prensa, coordinación con la agencia de publicidad para la compra de Publicity y búsqueda de canales de promoción complementarios. 
- Organización de eventos de presentación de soluciones informáticas y seminarios de actualización profesional.

- Creación y lanzamiento de Revista institucional orientada al segmento empresarial, con el objetivo de desarrollar awareness de marca que favorezca el desarrollo de programas de capacitación para ejecutivos.

- Análisis competitivo, pricing y desarrollo de nuevos productos en coordinación con las áreas técnicas especializadas y docentes. Identificación de oportunidades y demanda a través de focus groups, encuestas, implementación de buzon de sugerencias y entrevistas a alumnos y empresas al término de los programas de capacitación corporativos. 


\section{COMPETENCIAS PROFESIONALES}

Con el aprendizaje, know how, casuística y experiencia ganada en diferentes empresas durante más de 10 años acepté un nuevo reto profesional como DIRECTORA DE LA ESCUELA DE COMUNICACIONES DE LA UNIVERSIDAD CIENTIFICA DEL SUR, cuyos objetivos estaban totalmente asociados a las metas que ya habia enfrentado durante mi vida profesional y que puedo resumir en:

1. Crecimiento del posicionamiento, imagen y reconocimiento de la marca en todos los stakeholders

2. Planeamiento y repotenciación de la propuesta de valor y desarrollo de las capacidades competitivas de la marca

3. Plan de comunicación para los públicos internos y externos alineándolos a la estrategia de negocio

4. Fidelización y rentabilización de la cliente, incremento de la satisfacción y recompra de servicios

5. Desarrollo de la demanda, crecimiento del mercado e identificación de nuevas oportunidades de negocio

6. Desarrollo una cultura orientada a la calidad y mejora continua

7. Crecimiento de las ventas, ingresos y rentabilidad de negocio

De esta experiencia profesional, me brindó la oportunidad de trabajar las comunicaciones tanto en lo estratégico y lo operativo, como objeto y sujeto, como campo académico y práctico, como todista y especialista.

\section{2.a. Reflexión inicial:}

Experiencia y saberes diversos me fueron necesarios para abordar con éxito estos objetivos. Para propósitos de la presente sustentación, me concentraré en detallar la estrategia asociada a los planes operativos y tácticos donde las comunicaciones fueron tanto sujeto y medio, detallaré también los productos comunicacionales que creé y administré y que fueron los protagonistas la estrategia transformacional del clima y cultura, basados en un liderazgo orientado al logro de resultados.

Los productos comunicaciones que desarrollé, corresponden a todas las especialidades del ejercicio profesional donde un comunicador se desenvuelve en el mercado laboral: Periodismo, Medios audiovisuales, comunicación organizacional, Publicidad, y los gerencié con una visión orgánica, desde la creación de la estrategia hasta la ejecución táctico y operativa, en la responsabilidad de asegurar el logro de los objetivos corporativos que recibí como directora de comunicaciones.

Pero además, el planteamiento que pretendo aportar con la presente sustentación, es contribuir al reposicionamiento del perfil del Comunicador -formado en una universidad-, asociándolo a la capacidad de crear estratégicamente y gestionar empresarialmente, desde KPIs e indicadores de negocio, desmarcándose de la ejecución de lo táctico como el entendido campo natural de su acción profesional, y evidenciando la trascendencia de la carrera dentro de las primeras líneas en la estructura de las empresas, por su enfoque hacia el mercado y los públicos, su capacidad de responder en la resolución de problemáticas de negocio con un 
pensamiento creativo y crítico, haciendo uso tanto de lo cuantitativo como lo cualitativo para analizar, planear, sintetizar y ejecutar estrategias gestionándolas desde Kpis y métricas comerciales, financieras, de satisfacción, calidad y de marketing, pues este es el lenguaje de las empresas y de nuestros mercados competitivos.

Este reposicionamiento decidido, definiría las diferencias entre la formación técnica y la universitaria, dotaría al comunicador universitario de herramientas para transitar con mayor comodidad entre retos empresariales y afinaría su capacidad de análisis y aporte ante problemáticas de negocio.

Mi reflexión desde la comunicación organizacional, el periodismo, la publicidad y la comunicación para el desarrollo social y empresarial, es que la profesión cuenta con las capacidades que la estrategia moderna requiere para gerenciar sus productos, servicios y estrategia de mercado: Un enfoque muy directo en los públicos y en la administración de las expectativas de las audiencias internas y externas como norte para la toma de decisiones, un enfoque más humano como herramienta competitiva para el posicionamiento de la marca, un mindset convocante y colaborativo con un discurso centrado en las personas para desarrollar la identidad con la marca; y si bien todo lo descrito constituye el ámbito del Comunicador, reconozcamos que cerrar brechas formativas a nivel de gestión empresarial de productos y servicios, comprensión de las variables financieras e indicadores de negocio, administración y la gestión de los recursos humanos, permitiría un seniority del comunicador en espacios de dirección en la 1ra línea, donde no se puede navegar sin este tipo de conocimientos y capacidades. No tiene que ser excepcional que un Comunicador gerencie una organización, actualmente lo es, comparativamente con otros profesionales formados en la universidad. Hablando de la orientación formativa de institutos y universidades, parece haber un espacio de reflexión aquí....

\section{2.b. ANTECEDENTES}

Como Directora de escuela recibí el encargo de incrementar los ingresos y rentabilidad de la escuela, reducir la deserción de estudiantes, incrementar la satisfacción con el producto académico y generar una comunidad universitaria comprometida con la marca.

Luego de hacer una evaluación situacional que incluyó el análisis del mercado de escuelas de comunicación en Lima, sus propuestas de valor, las variables competitivas del producto académico, realización de entrevistas a estudiantes de todos los ciclos, egresados y alumnos desertores, profesores, ex profesores, personal de planta y empresas del sector que potencialmente debían absorber laboralmente a los egresados y el análisis del historial y data del negocio en los últimos 5 años; elaboré el plan estratégico del negocio donde el plan de Comunicación interno y externo fueron las bases de la transformación de la situación inicial en un caso de éxito. Los problemas

1. Falta de crecimiento del negocio durante 5 años. En un mercado donde se habían lanzado otras escuelas de comunicación que ya venían creciendo en proporciones significativas, evidenciadas por el crecimiento del número de estudiantes por ciclo, precios promedio del servicio, ingresos considerando pxq), 
recordación espontánea de marca en el público objetivo, sin tomar en cuenta para el análisis, a aquellas escuelas de comunicación ya existentes y más consolidadas.

2. Mínimo número de ingresantes en 1 única campaña al año debido al bajo número de postulantes

3. Altas tasas de deserción estudiantil y altas tasas de insatisfacción e incertidumbre en alumnos de todos los ciclos. Bajas tasas de recomendación del producto

4. Falta de potencia del producto frente al mercado

5. Falta de estrategia de branding, marketing y comercial.

6. Bajo reconocimiento de la marca y peor aún de la existencia de la escuela en el mercado.

7. Clima laboral de inercia y orientado cumplimiento de las tareas, evidenciando la falta de un plan estratégico del negocio, planes operativos y tácticos que movilicen y orquesten a toda la estructura en su conjunto para el logro de una visión compartida.

\section{2.c. OBJETIVOS}

Las dimensiones donde concentré mi gestión a nivel de comunicaciones para lograr los objetivos de crecimiento comercial de la escuela fueron:

Dimensión 1 :

Rediseño y Creación de la propuesta de valor para el desarrollo de nuevas capas de valor del servicio

Dimensión 2 :

Experiencia cliente y cultura interna para el alineamiento y viabilidad de la estrategia

Dimensión 3 :

Ejecución del Plan de comunicación y nuevo posicionamiento competitivo.

\section{DESCRIPCION DEL CASO}

En base al análisis de mercado (competidores, análisis foda y canvas, análisis de la data comercial y financiera del negocio), mi primer objetivo fue redefinir el mercado objetivo y la propuesta de valor correspondiente.

Para lo cual construir un nuevo producto soportado sobre variables de mercado donde era posible competir con éxito, gerenciando simultáneamente tanto la visión académica como la comercial, y estructurando un discurso que vincularían a la escuela con sus usuarios y stakeholders. 


\section{Rediseño y Creación de la propuesta de valor:}

i. Antecedentes:

Hasta antes de mi gestión, el producto era uno solo: "Carrera de Comunicación y Publicidad", con un perfil de egresado confuso, pues incluía simultáneamente elementos formativos de Periodismo, audiovisuales y organizacional, pero no había coherencia en cuanto a distribución de tiempo para la formación y profundización en Publicidad, como indicaba la promesa de venta, Asimismo la población estudiantil tenía expectativas de poder ejercer al menos 2 de las 4 especialidades en algún momento de su vida profesional y, la 1ra promoción de egresados, se sentía desorientada respecto a cuales eran sus competencias específicas como profesionales de la científica, aunque pensaban que en mayor grado habían sido preparados para ejercer la comunicación organizacional.

Por otro lado, las horas prácticas no producían, en ninguna especialidad, productos comunicacionales con el valor para representar el peso de la formación académica y práctica de la universidad, así como el awareness de marca asociado a la escuela era casi inexistente, lo cual desmoralizaba a los estudiantes.

El mercado ofrecía ciertamente propuestas que cubrían todo el espectro formativo anhelado por estudiantes de comunicaciones, especialidades, laboratorios, infraestructura, talleres, etc, y las cifras del crecimiento de estudiantes en otras escuelas crecían o se mantenían, mientras que el panorama era completamente distinto, "de este lado del rio"...

El único soporte comunicacional existente fue un boletín elaborado por un colaborar de la escuela, donde se publicaban eventos o novedades de la escuela, cada 2 meses, el cual era subido, por el área de marketing, en las redes sociales de la universidad. No habia un plan de comunicación de la escuela, ni una orientación hacia producir una identidad del producto, o una estrategia para conectar con sus públicos, o un discurso comercialmente capaz de incrementar el volumen de postulaciones y, tratándose de una escuela de comunicaciones, no se contaban con los canales o las plataformas de difusión para evidenciar capacidades que permitieran su posicionamiento en el mercado.

\section{ii. Incremento de la atractividad. Variables competitivas y diferenciales}

El objetivo se centró entonces en la creación de una propuesta de valor que convoque a estudiantes de las 4 especialidades ofrecidas en el mercado, con un discurso orientado específicamente a los intereses de cada uno, pero al mismo tiempo vinculante y complementario, acorde con el interés de incrementar la capacidad de aporte profesional y empleabilidad de los futuros profesionales, incrementando la atractividad del servicio, cubriendo un mayor espectro de mercado, y cuya evidencia se refleje en el incremento del número de postulantes, ingresantes y el volumen crecimiento de la masa de estudiantes en la escuela.

Se validó la estrategia con estudiantes propios y de otras escuelas, con empresas orientadas a las comunicaciones, profesionales y postulantes. 
El siguiente fue el nuevo perfil del cliente al cual íbamos atender y la nueva propuesta de valor que construiría para él, que reorientaron todos los esfuerzos estratégicos académicos y comerciales:

"El egresado de la Carrera de Comunicaciones de la Universidad Científica del Sur, es un comunicador integral, que ha sido formado simultáneamente en las 4 áreas de especialización profesional: Periodismo, Publicidad, Audiovisuales y Comunicación Organizacional, siendo capaz de crear propuestas comunicacionales multiplataformas desde la fase del planeamiento comunicacional integral, dirección de la gestión periodística, publicitaria, audiovisual y organizacional simultánea, el manejo operativo de herramientas técnicas y metodologías propias de cada especialidad, y la evaluación y auditoría de la comunicación estratégica integral (...)

Esta formación integral y multifuncional incrementa la capacidad de empleabilidad del egresado, permitiéndole generar valor multiplicado en las organizaciones y en su línea de carrera (...), ofreciendo al mercado capacidades profesionales en las diversas áreas de especialización donde se desenvuelve un profesional de las comunicaciones".

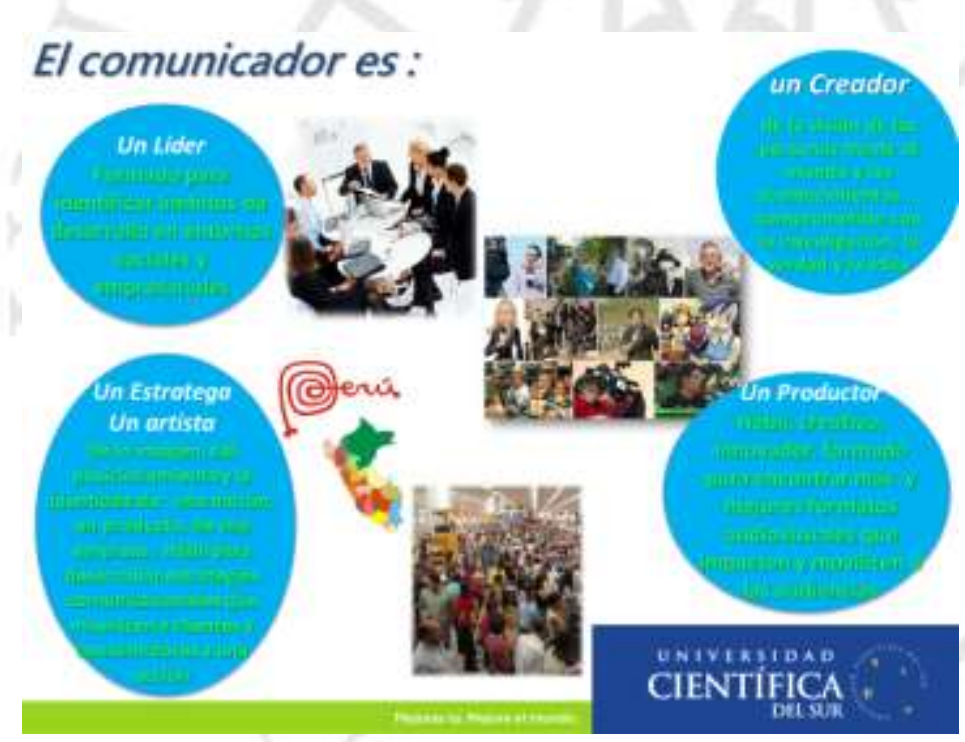

Respondiendo a este nuevo perfil, planifiqué la transformación del producto académico, y construí el plan de comunicación interno y externo para sensibilizar a las audiencias, modificar su percepción del producto, re-posicionar a la escuela en el mercado y movilizar a los públicos alrededor de la marca.

El plan de comunicación se centró en la creación de los laboratorios de desarrollo profesional que permitían una formación especializada en cada área donde los comunicadores se desenvuelven profesionalmente, en la satisfacción de los estudiantes viviendo su formación altamente orientada a la práctica, en una vida universitaria altamente activa, centrada en el desarrollo de las competencias personales y profesionales demandadas por el mercado laboral. 
La creación de cada uno de los LDP, respondió a la creación de una propuesta de valor más poderosa en términos de competitividad de producto en el mercado, pero al mismo tiempo, ellos fueron la solución a la falta de una línea de comunicación y de contenidos que articulen un posicionamiento interno y externo, una sinergia entre la actividad académica y las exigencias comerciales de la escuela, una personalidad e identidad que a nivel de satisfacción de estudiantes y venta lograra captar la atención de los postulantes y retener a los estudiantes.

Los LDP respondieron a ambos objetivos como Directora, asegurar un producto académico de excelencia, fue una labor muy demandante pero respondía a un ámbito interno donde era posible actuar e innovar sin mayores consideraciones, además del cumplimiento de normatividad del organismo supervisor, sin embargo asegurar la salud financiera de la escuela, a nivel de ingresos y posicionamiento, era un reto que consideraba una actuación tanto a nivel interno como externo, y que en mucha medida venia dependiendo de un área central (Marketing) como responsable de difusión y promoción de la escuela, la cual no crecía en postulantes, ingresos, Ebitda. El esfuerzo comercial y de marketing que necesitaba la escuela, considerando que en esos momentos, no se destinaba presupuesto alguno para publicidad ATL que el área de marketing corporativo no habia logrado proponer una estrategia que lograra atraer alumnos hacia la escuela, que sus esfuerzos estaban concentrados en la publicidad genérica y en la publicidad de carreras más grandes en términos de contribución al negocio, entre otros aspectos, sentaron las bases para organizar los esfuerzos de la escuela de manera sinérgica entre los retos académicos y comerciales gerenciándolos simultáneamente para obtener el éxito del negocio.

La generación de contenido se soportó en el producto académico, y la creación proactiva de los canales de difusión de los contenidos de la escuela, aceleraron la visibilidad de la escuela y mejoraron su atractividad, evidenciándose este cambio en el crecimiento decidido del número de postulantes en tasas nunca antes registradas.

La organización y lanzamiento constante de un portafolio de charlas, conferencias, cursos, seminarios sin costo, (con profesionales emblemáticos de las diferentes especialidades), para públicos actuales y externos, incrementaron la percepción de valor del servicio, desarrollando la oportunidad de ampliar la base de datos de clientes potenciales, gestionar estrategias masivas "personalizadas" y generar tráfico en la escuela como medida inicial para desenvolver luego una estrategia de captura de mayores volúmenes de postulantes.

La planificación y ejecución de proyectos, concursos, convocatoria permanente de estudiantes y el incremento de la actividad estudiantil más allá de las horas de clases, propiciaron un clima de protagonismo del estudiante, de aceleración en el proceso de enseñanza-aprendizaje, de cambio en la metodología de aula hacia el campo, donde pronto tanto profesores, estudiantes y líderes de bloques académicos se vieron envueltos dentro de un clima de proactividad, reto, desarrollo de destrezas, colaboración, reconocimiento y sentimiento de realización, empezando así la transformación de la experiencia cliente. 


\section{1.a. Creación de 4 especialidades:}

Dirigí el cambio del plan de estudios como elemento básico académico en la construcción de la propuesta de valor, organizando cursos y docentes en los bloques correspondientes, seleccionando a los lideres por bloque y desarrollo del plan de trabajo de cada bloque.
a. "Publicidad",
b. "Comunicación organizacional y para el desarrollo",
c. "Periodismo" y
d. "Producción audiovisual"

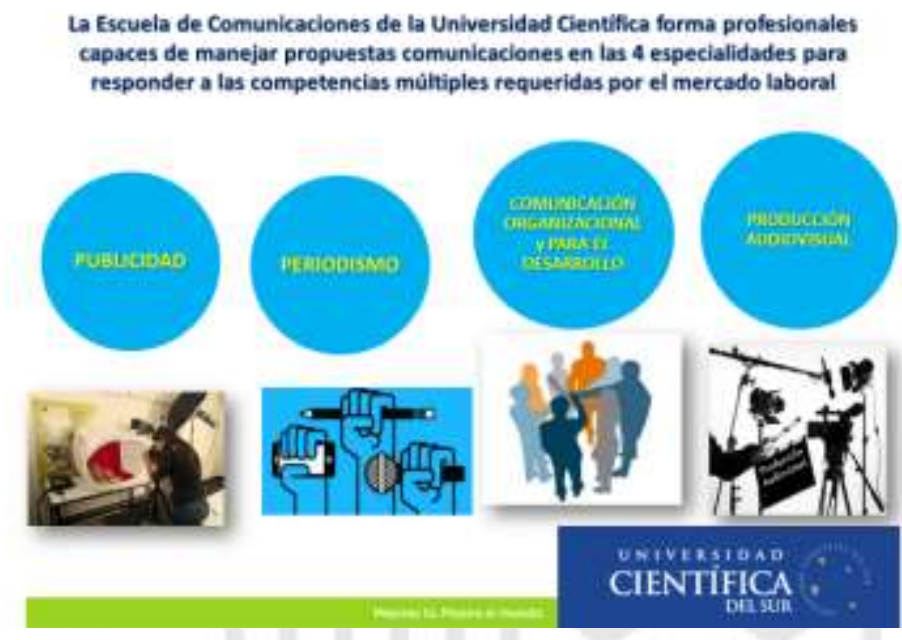

En esta etapa, fueron retos muy interesantes la modificación del plan de estudios ante Sunedu, la malla curricular, cambio del creditaje, reorganización de cursos obligatorios y la estructuración y creación de cursos electivos especializados y/o compartidos con otras escuelas y facultades, además de cuidar simultáneamente la rentabilidad del proyecto y de las operaciones, asegurando al menos mantener sino reducir los costos, asegurar la optimización en la la ocupabilidad de aulas asegurando el número mínimo de alumnos para abrir cursos y, la organización de una cuidadosa programación de cursos para atender la demanda de los estudiantes, considerando que la escuela no tenía el número suficiente de alumnos para abrir todos los cursos con el número mínimo exigido por la universidad.

Este fue el inicio de una gran transformación, que se dio inicialmente, sin recursos adicionales a aquellos con los que ya contaba la escuela, mi gestión se orientó al logro de resultados progresivos y permanentes, pruebas y correcciones rápidas, sincronización de las acciones tácticas con la línea de comunicación para lograr la movilización de los equipos de trabajo, alumnos, autoridades, staff administrativo y exposición externa a través de uso de distintos medios y canales informativos. 


\section{1.b. Creación de los LDP (Laboratorios de desarrollo profesional)}

En este contexto se inició la creación de cada uno de los LDP, dedicados a la producción de contenidos de las 4 areas de especialización, como parte de la formación académica, creándose un ambiente de alta expectativa y motivación entre los estudiantes y área docente, quienes fueron organizados como protagonistas de este cambio.

Cada especialidad fue lanzada con el soporte de un LDP donde las habilidades de la especialidad seria desarrolladas bajo el liderazgo de un Líder de bloque (profesor principal) que aseguraría el cumplimiento de plan de trabajo del semestre, para todos los cursos del bloque, supervisando el avance y logro de los productos académico (comerciales) según la dirección de la escuela habia aprobado antes del inicio de cada semestre.

\section{Medologia:}

Basada en la experiencia directa y temprana a la carrera, desde el primer ciclo, nuestros alumnos tienen un entrenamiento especifico en los 4 ámbitos profesionales del comunicador $y$ son impulsados $y$

orientados para empezar a construir sus evidencia de èxito a travès de nuestros:

\section{LABORATORIOS DE DESARROLLO PROFESIONAL (LDP)}

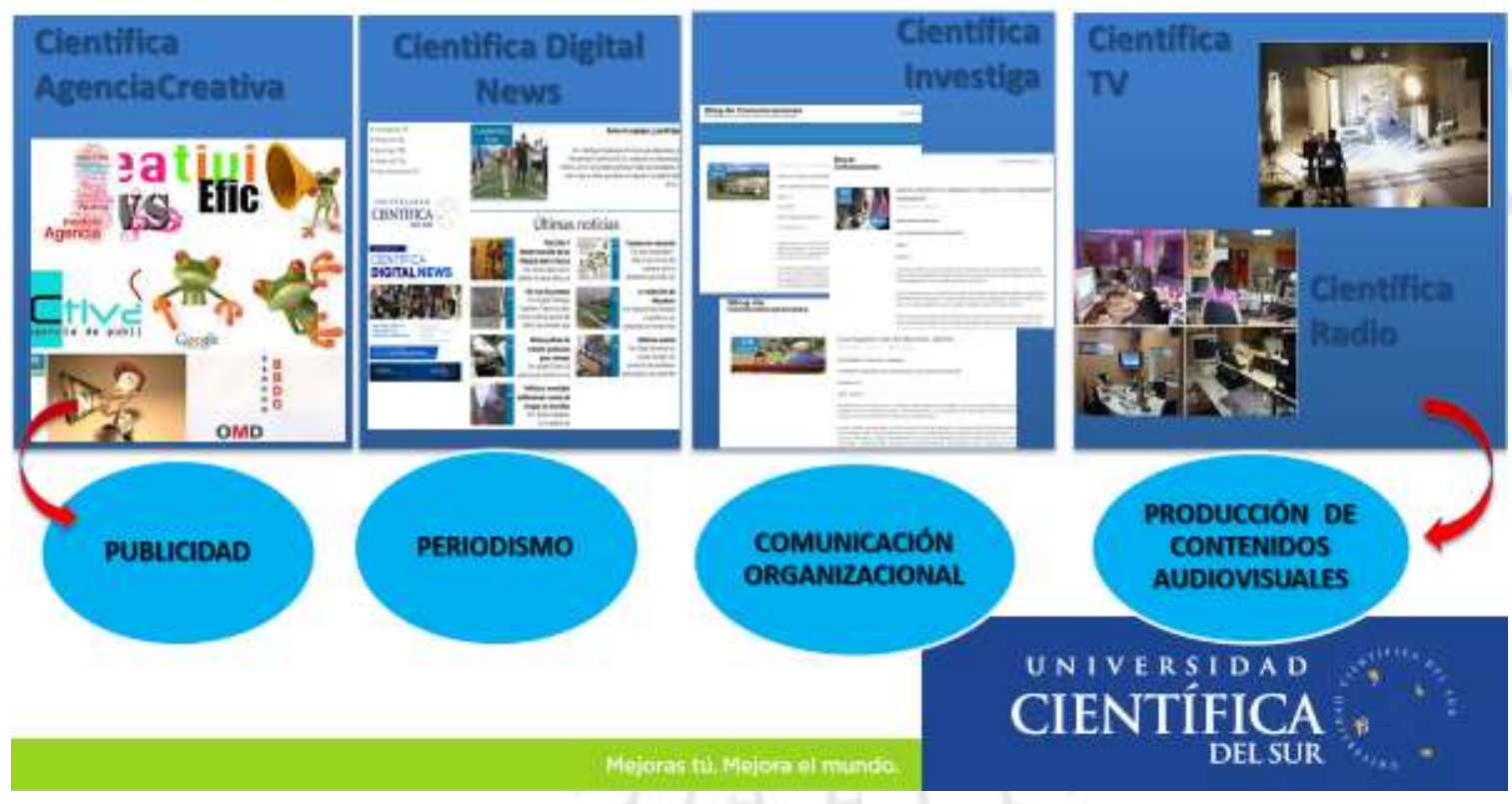

Los productos académicos fueron bautizados como "entregables", y tanto líderes como staff de profesores tenían como misión la perspectiva de desarrollar en clase, de acuerdo a los silabus reestructurados de toda la malla curricular, "elementos capaces de tener impacto de marketing a nivel interno y externo".

El formato de "entregables" se cumplía considerando 2 escenarios:

- entregables obligatorios de curso

- $\quad$ entregables de los laboratorios de desarrollo profesional al cual pertenecia cada curso. 
De esta forma todos y cada uno de los alumnos de la escuela, en todos los ciclos, tenia la misión de trabajar la creación de entregables, era el profesor quien seleccionaba los mejores y según lograra el mayor numero de entregables de calidad en su aula, su calificación de perfomance era mayor o menor.

Ya no era posible contar con profesores que se limitaban a dictar sus horas de clases sin dedicarse a la calidad de los resultados de la gestión de los esfuerzos de los estudiantes en clase. Desde la dirección, pasando por el líder del bloque, el profesor empezó a trabajar por objetivos, concretos y medibles. Desde la organización de la participación de los alumnos en cada uno de los laboratorios, que se lograba a través de la postulación a diferentes cargos, similares a los cargos existentes en empresas reales en el sector, hasta el desarrollo de proyectos emblemáticos, los cuales normalmente eran requerimientos reales de la misma dirección, de las diferentes áreas de la universidad y más delante de clientes externos, el aula de clase se empezó a convertir en una célula de producción, donde líder, profesor y alumno, trabajaban con casuísticas reales y con KPIs que daría cuenta del tipo de labor que desarrollaba como profesor de la escuela.

La filosofía de enseñanza, orientada a la practica en el aula de clase fue el primer elemento de cambio y la estrategia de comunicación y alineamiento de todo el staff se baso en 4 objetivos de escuela claros:

\begin{tabular}{|l|l|}
\hline \multicolumn{1}{|c|}{ Objetivo académico } & \multicolumn{1}{c|}{ Objetivo comercial } \\
\hline Formación práctica de los estudiantes & $\begin{array}{l}\text { Atractividad metodológica y generación } \\
\text { de contenido comercial }\end{array}$ \\
\hline $\begin{array}{l}\text { Especialización en las 4 areas de la } \\
\text { comunicación }\end{array}$ & $\begin{array}{l}\text { Construcción de elementos para la } \\
\text { comunicación y marketing para } \\
\text { capturar audiencias con discursos } \\
\text { específicos }\end{array}$ \\
\hline $\begin{array}{l}\text { Potenciamiento de la capacidad de } \\
\text { empleabilidad del estudiante }\end{array}$ & $\begin{array}{l}\text { Evidencia del éxito de la formación de } \\
\text { la universidad }\end{array}$ \\
\hline $\begin{array}{l}\text { Relación líder-alumno- profesor } \\
\text { orientado a desarrollar sus } \\
\text { capacidades y talentos }\end{array}$ & $\begin{array}{l}\text { Aseguramiento de la experiencia } \\
\text { usuario para incrementar la } \\
\text { recomendación }\end{array}$ \\
\hline
\end{tabular}

Cada uno de estos 4 objetivos formaban parte del discurso permanente de la escuela, tanto a nivel interno como externo, dando contundencia a una linea estrategica clara y orientada totalmente a los insights identificados en el estudiante y a lograr los objetivos del negocio.

\section{1.b.1. Comunicación de influencia y movilización. Las convocatorias:}

En la comunicación de 4 objetivos de escuela, estudiantes, docentes y líderes de bloque, experimentaban un nivel de expectativas, que se tangibilizó en la oportunidad 
de empezar a crear una personalidad propia como comunicador aun dentro de la universidad.

La estrategia de movilización incluyo la creación de escenarios de exigencia reales, cronogramas, entregables, KPIs de performance, medición en la calidad de proyectos, evaluación 360 de habilidades personales para el manejo de personas, orientación a resultados, capacidad de mantener activados a todos los equipos de estudiantes o "Unidades Productivas", término acuñado para denominar a cada equipo de trabajo a cargo de un proyecto entregable o emblemático, en cada laboratorio de desarrollo profesional).

Las estrategia de comunicación de las convocatorias se realizaban a nivel de lanzamiento de inicio de ciclo, cada ciclo, cada año y mostraba los desafíos en cada LDP y los beneficios que significaba su desarrollo, asimismo, parte de la estrategia fue el diseño de convocatorias tipo "proceso de selección".

\section{Convocatorias}

\section{Científica Creativa (Publicidad) y Científica Radio (Producción audiovisual)}

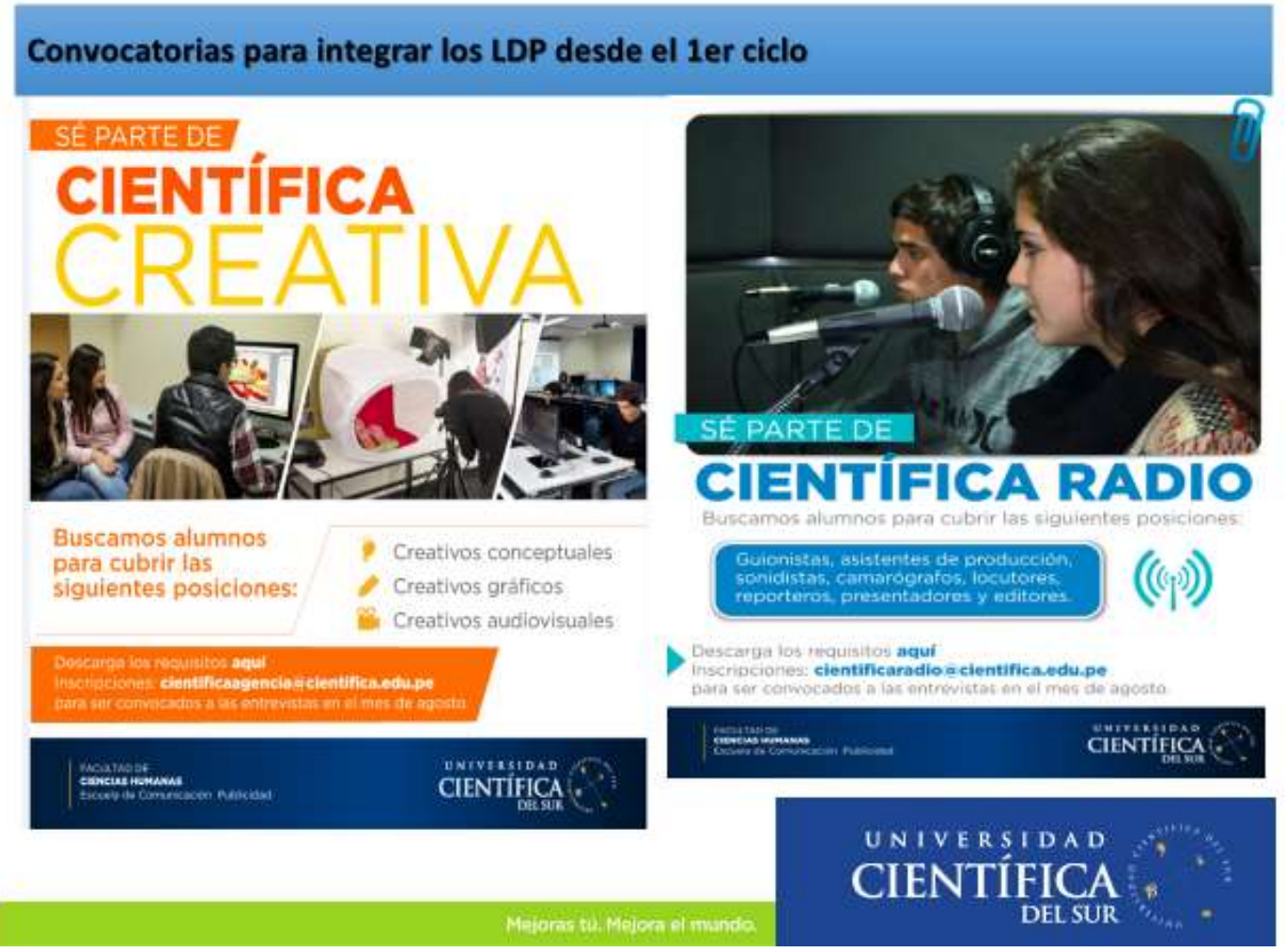




\section{Científica TV (Producción audiovisual) y Científica Digital News (Periodismo)}

\section{Convocatorias desde el 1er ciclo}

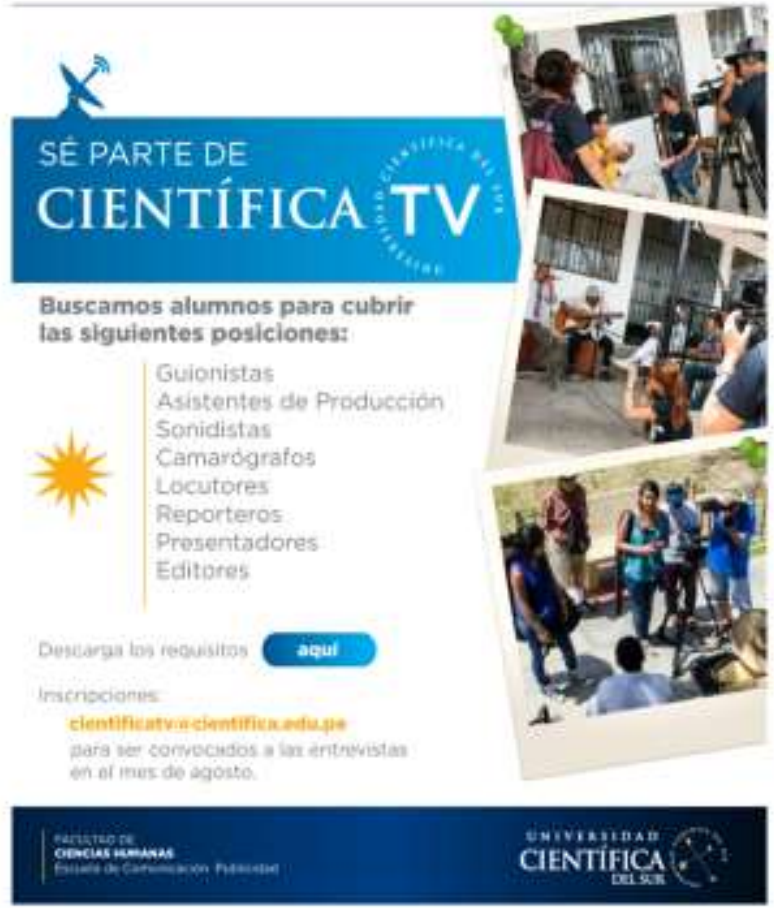

SÉ PARTE DE
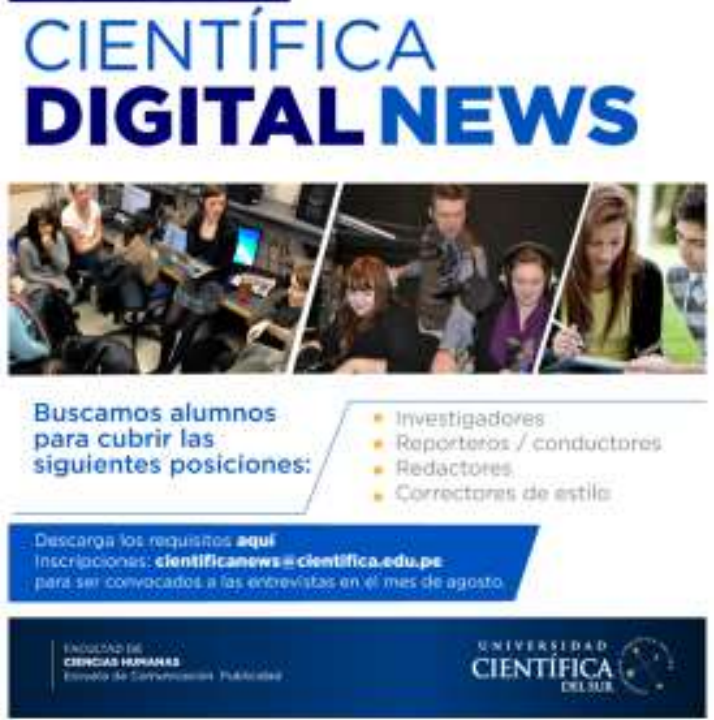

CIENTIFICA:

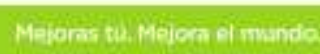

UN I VERSIDAD:

CIENTIFICA :

DEL SUR

\section{Científica Investiga (Comunicación Organizacional)}
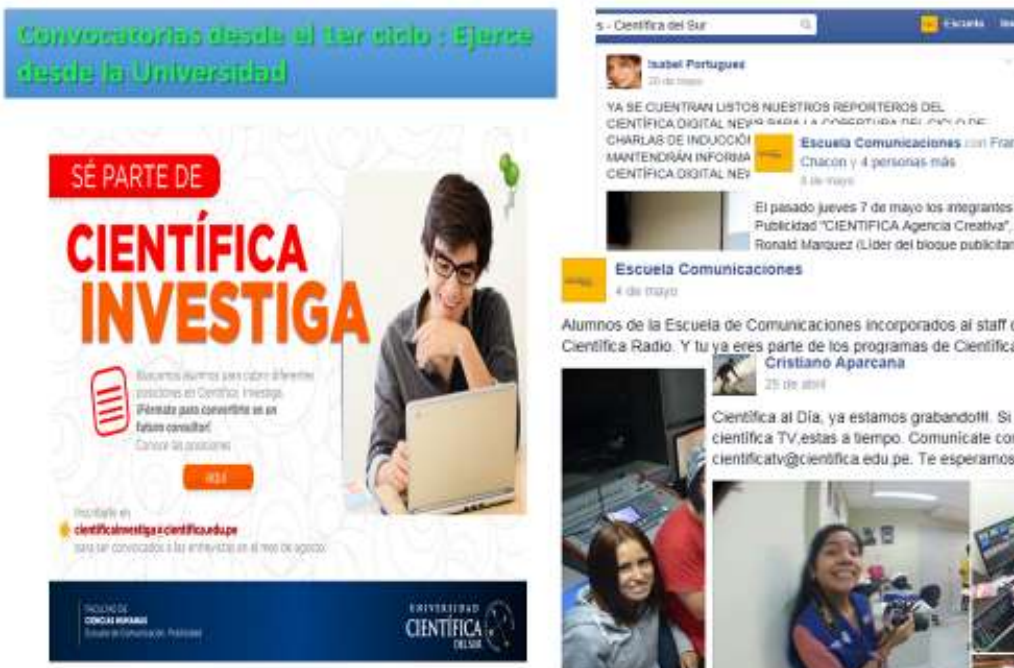

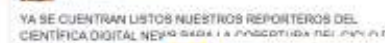

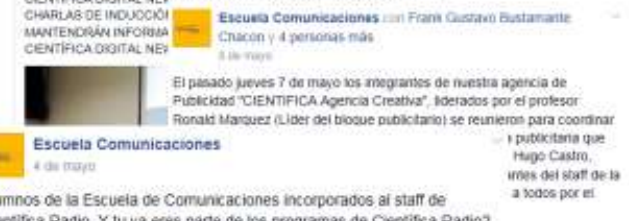

Cenalica Radio Y tu ye eres pánte de los programas de Ceenifica Radio

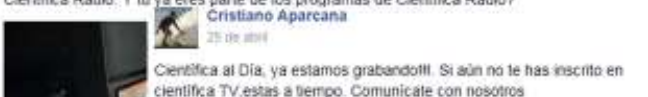
cientifica Ty esyas a Derrpo comunicale con nosotros

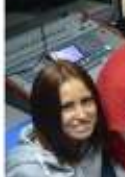
cientiscatugigientinca edu pe. Te esperarn

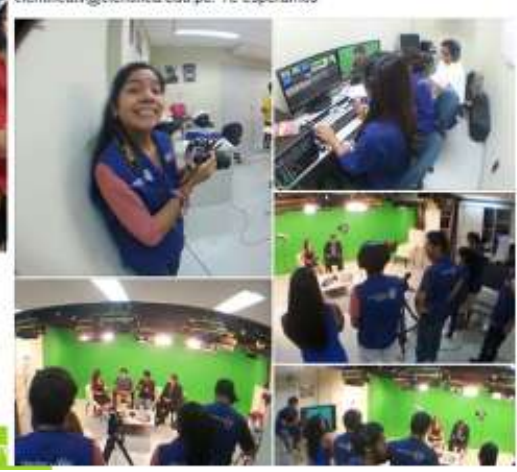




\section{1.c. Proyectos:}

Lanzamiento semestral de proyectos del ciclo (planes de trabajo) por bloques de especialización

Dentro de la modificación realizada en la curricula y plan de estudio, la participación en los proyectos en los LDP por parte de los alumnos, pasó a convertirse en un requisito indispensable para cumplir las exigencias de graduación. Por lo cual tanto por motivación como por deber, la escuela lograba los objetivos de evidenciar una formación práctica, beneficiosa para el alumno, así como la generación permanente de contenidos, beneficiosa también para la imagen de la escuela.

La participación simultánea de alumnos de todos los ciclos en los proyectos emblemáticos dentro de cada LDP, significo a nivel de comunicación, una variable diferencial frente de otras universidades donde el uso de los laboratorios es priorizado para los alumnos de los últimos ciclos y solo para los proyectos propios del curso. Esta diferencia constituyo también un factor de alta motivación, satisfacción para los estudiantes y los proyectos más representativos de cada laboratorio, fueron usados ampliamente dentro del discurso de marketing y en el plan de comunicación externo.

\section{1.d. Concursos}

Antes del inicio de cada ciclo académico, identificaba junto con los líderes de bloque los concursos de mayor visibilidad donde la escuela debía participar, organizándose para lograr la visibilidad de la marca.

Mucho éxito representó para la escuela, en términos del incremento de postulaciones, la participación en el concurso nacional de cortometrajes donde una de las producciones "Reminiscencia", finalista en el concurso internacional organizado por FENACO en octubre del 2015 y la producción del cortometraje "Por siempre mia" en el 2016. 


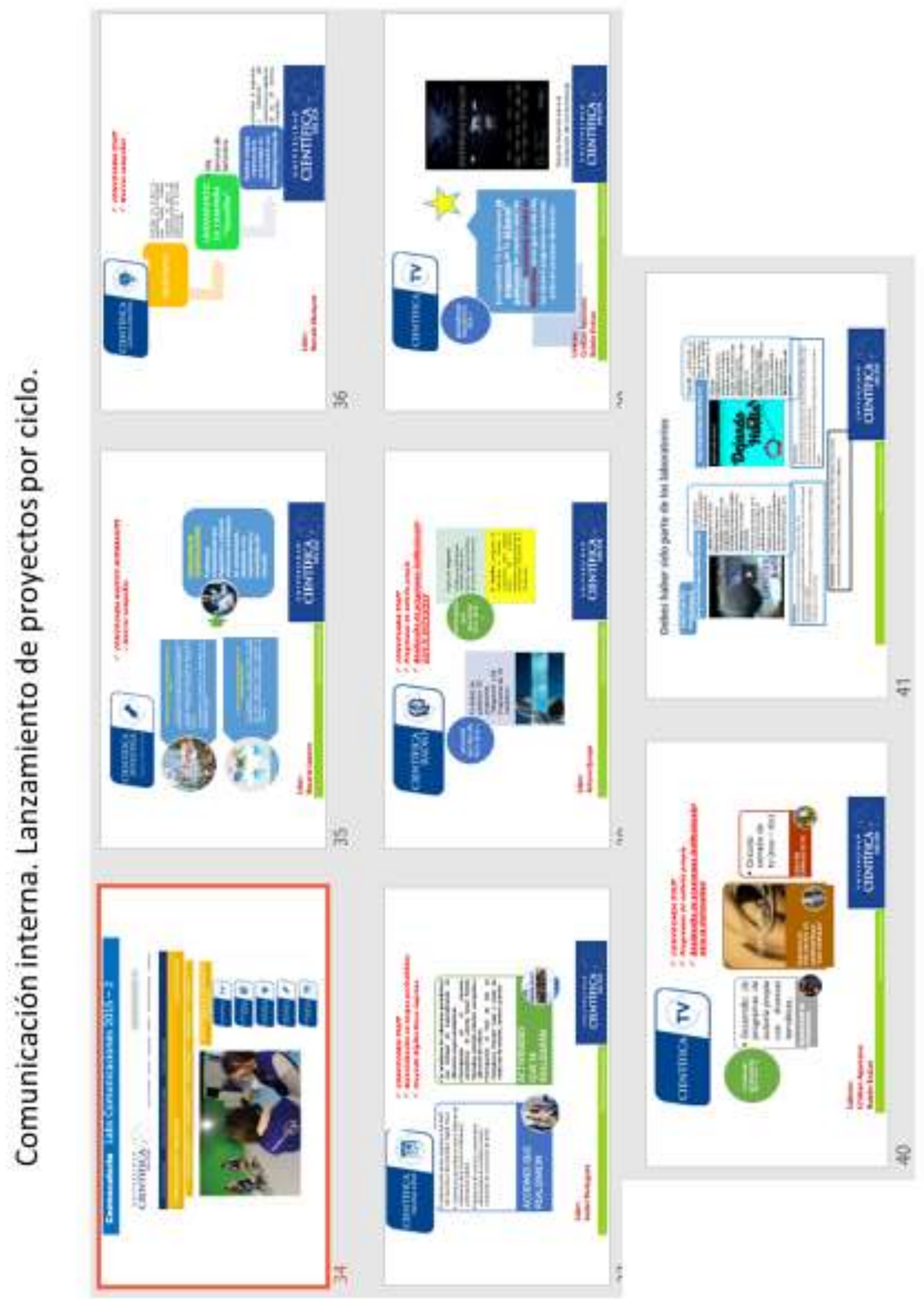




\subsection{Experiencia cliente y cultura}

El logro de los objetivos estratégicos eran posibles únicamente alineando los esfuerzos de la dirección con el equipo de trabajo, capacitando e implementando los mecanismos para definir una cultura automáticamente orientada al logro de objetivos concretos y medibles, donde cada líder de bloque y profesor del staff sabía que es lo que se esperaba de él, como sería evaluado y cuáles eran los nuevos retos en cada ciclo de la carrera, impulsándolo todo ello en conjunto al logro de sus indicadores, a la creación constante, la actualización de materiales, ejecución de proyectos, etc..

Para la creación de una cultura orientada a ubicar al estudiante en el centro de la actividad de la escuela, asegurar su experiencia en aulas, buscar la mejorara constante de la propuesta de valor y "automatizar" la orientación de los colaboradores hacia los objetivos académicos y comerciales de la escuela, diseñe y lancé nuevos KPIs de evaluación de performance de mi equipo de trabajo (5 lideres de bloque, staff de profesores) orientándolos al cumplimiento de los nuevos objetivos estratégicos académicos, que eran al mismo tiempo la base de la linea de comunicación de la escuela, la generación de contenidos y la construcción de la evidencia de éxito de la formación de comunicadores en la ucientifica.

\section{2.a. Estrategia de fidelización. Procesos y construcción de KPls de experiencia cliente.}

Basé la estrategia de fidelización de alumnos en el rediseño y aseguramiento de nuevos estándares de servicio en los procesos del delivery del servicio, los cuales eran ejecutados por el staff de profesores, coordinadores y líderes de bloque, y que en adelante fueron medidos directamente por mi Dirección desde 5 enfoques y KPIs asociados a su cumplimiento:

1. Enfoque académico de los cursos hacia la práctica, para alumnos desde el 1ro al $10 \mathrm{mo}$ ciclo.

Aseguramiento a través del diseño de KPls de performance para profesores y líderes de bloque: en el cumplimiento de los silabus reestructurados con la exigencia de la creación de 4 a 7 "entregables" en cada curso.

2. Enfoque orientado a la creación de la evidencia de éxito del estudiante haciéndolo más competitivo para un rápido ingreso al mercado laboral

Aseguramiento a través del diseño de "cuadernos de evaluación del estudiante" (CEE), basado en la publicación de "entregables" listos y aptos para su publicación en las plataformas de la escuela. 
3. Enfoque humanista para la formación de profesionales con valores y conciencia social

Aseguramiento a través de la implementación de KPIs para líderes de bloque y "CEE" por participación en proyectos de responsabilidad social universitaria de acuerdo a los proyectos aprobados y lanzados por la dirección de la escuela.

4. Proceso de formación orientado al contacto permanente con profesionales de las comunicaciones en las 4 especializaciones, a través de seminarios, charlas, debates, paneles, mesas de trabajo, asesorías, calificación de proyectos, entre otros espacios.

Aseguramiento a través del diseño de KPIs para profesores, el cumplimiento de la incorporación como expositores visitantes a profesionales en ejercicio.

5. Acercamiento intensivo con el sector productivo para el desarrollo de proyectos profesionales rentables y con miras a la creación de unidades de negocio dentro de la escuela.

Aseguramiento a través del diseño de KPIs para profesores y líderes de bloque para el desarrollo de trabajos profesionales para clientes reales, con oportunidad de ser facturables y evaluados para la creación de unidades de negocio.

Para el cumplimiento de estos 5 enfoques y la comunicación y socialización de los kpis de performance del staff de profesores y coordinadores, ejecute capacitaciones y permanentes presentaciones, brindando asimismo empowerment a los líderes de bloque, desentralizando la supervisión de los procesos académicos pero controlando cada uno de ellos con indicadores claros y formales.

\section{Comunicación y Lanzamiento de los 6 objetivos para docentes y líderes asegurados a través de KPIs de performance}

1. Enfoque y Metodología orientada al ejercicio profesional desde los primeros ciclos

\begin{tabular}{l} 
LABORATORIOS DE DESARROLLO \\
PROFESIONAL POR ESPECIALIDAD \\
Los estudiantes desde el 1er ciclo \\
postulan y participan en nuestros \\
laboratorios de Desarrollo \\
profesional ejerciendo labores y \\
cargos propios de la profesión en el \\
mercado \\
- "Científica Creativa": agencia \\
publicitaria \\
- "Científica TV": Canal de Tv on \\
demand \\
- "Cientifica Radio": Cabina y \\
emisora de radio profesional \\
- "Científica Digital News": \\
Periódico digital \\
- "Científica Investiga": Blog \\
consultivo para comunicadores \\
consultores \\
\hline
\end{tabular}

2. Enfoque orientado a la creación de la evidencia de éxito

\begin{tabular}{|l}
$\begin{array}{l}\text { Progresivamente el alumno } \\
\text { empieza a construir el respaldo } \\
\text { que mostrará al futuro } \\
\text { empleador en su hoja de vida, } \\
\text { ahi se evidenciara la } \\
\text { experiencia que el egresado ha } \\
\text { venido ganando durante sus } \\
\text { años de estudio, en el ejercicio } \\
\text { de la profesión, en las 4 } \\
\text { especialidades. De esta } \\
\text { manera nuestros estudiantes } \\
\text { tienen la oportunidad de } \\
\text { diferenciarse y destacar frente } \\
\text { otros postulantes, contando } \\
\text { con toda una metodología } \\
\text { orientadas a este fin y con las } \\
\text { plataformas comunicaciones } \\
\text { que la escuela pone a su } \\
\text { disposición. }\end{array}$ \\
\hline
\end{tabular}


3. Enfoque Humanista orientado a la formación de estudiantes con conciencia social

\section{- En nuestro bloque de Comunicación organizacional, nuestros cursos tienen una orientación práctica a la realización de acciones de campo, de esta forma los alumnos pueden vivir la concepción y ejecución de estrategias de RS como herramienta de comunicación corporativa de una institución.}

Escuela Comunicaciones 7 do juna

Alumnos del curso de Imagen instutucional y Reputaciôn de la carrera de Comunicación y Putididad, reatizaron una vista a ta zona de Pamplona Atta lievando el programa 'Siembra Esperanza', como parte de sus actindades de proyección social.

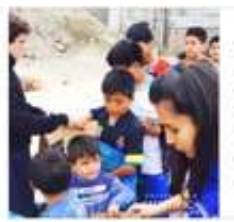

Alumnos de Comunicación y Publicidad llevan a Pamplona el programa Siembra Esperanza | Digital New

Alumnos dei curso de imagen innatuicional y.

camificandure en ejercicio de las comunicaciones
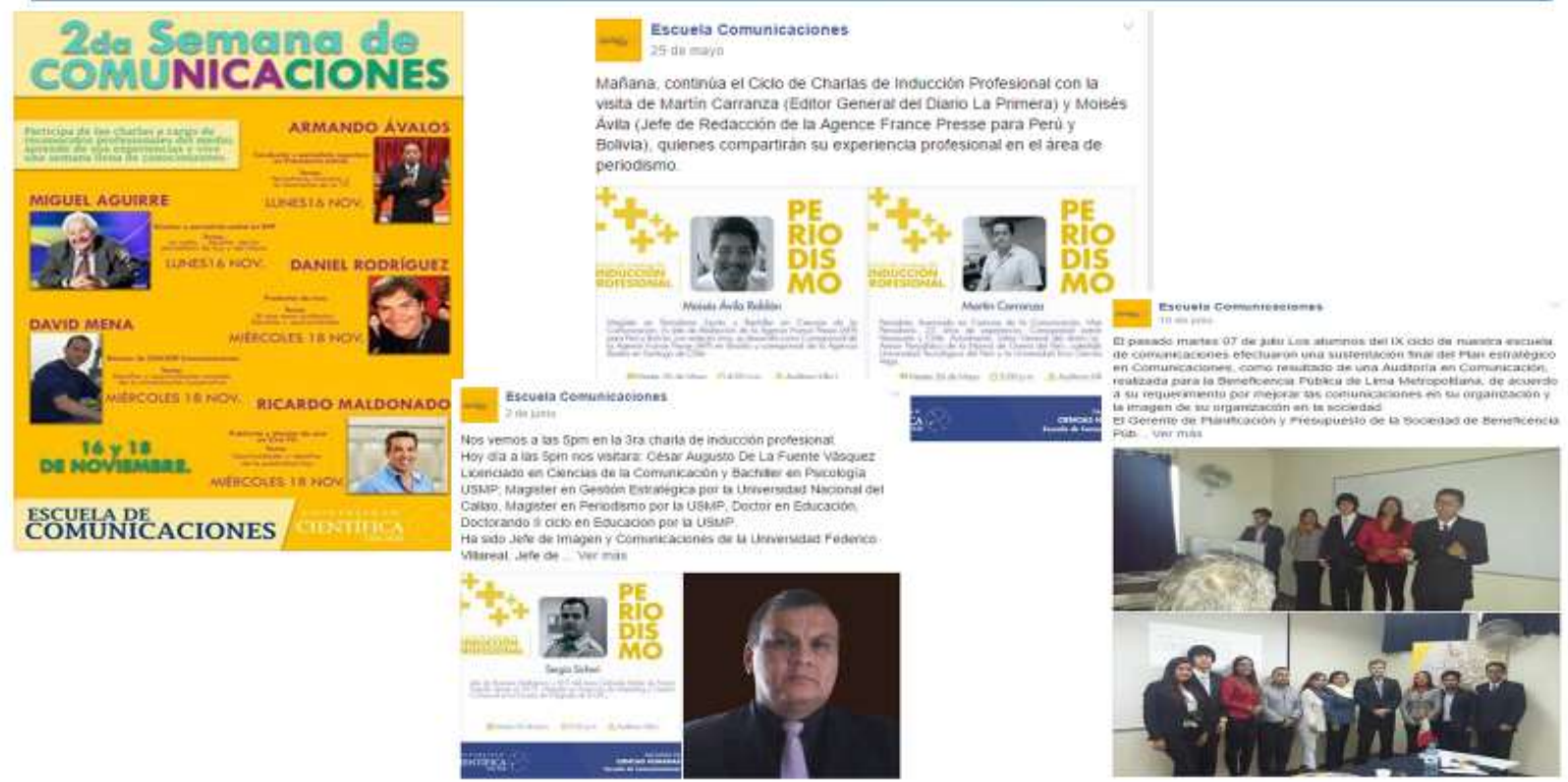


\section{Objetivo Estratégico 5}

Desarrollar alianzas con el sector productivo para producciones, proyectos 0 servicios producidos por de la escuela

\section{Objetivos Específicos}

11. Identificar instituciones con marcas estratégicas, para ofrecer nuestra capacidad de realizar producciones aprovechando la creación de los laboratorios de desarrollo profesional, buscando generar futuro nuevos ingresos para el negocio

\section{- Lograr acuerdos de mutuo beneficio con 2 instituciones por año}

- Desarrollo de un plan de comunicación con empresas privadas y públicas para obtener convenios de practicas y empleos para alumnos de comunicaciones

\section{Objetivo Estratégico 6}

Consolidar la calidad de la formación profesional académica por competencias para nuestros alumnos

\section{Objetivos Especificos:}

12. Evaluación y selección de docentes con trayectoria reconocida en el mercado laboral

13. Establecer el sistema de evaluación del docente, consolidando la correspondencia entre meritocraciay labor (1 premio por ciclo) evaluando:

- Cumplimiento del silabusy cronograma de entregables (7 entregables por ciclo)

- Evaluaciones aleatoreas de la escuela (on going 2 veces al año)

- Participación en las actividades de la escuela (exposiciones, publicaciones en los laboratorios, participación en eventos internosy externos) definidos desde el inicio del ciclo

14. Mantener 2 reuniones de coordinación por ciclo con los docentes (incorporar coordinación académica)

15. Consolidar el equipo de lideres a cargo de los diferentes bloques para asegurar calidad y producciones

16. Incorporaruna jornada anual de capacitación y motivación al docente 


\section{2. b Comunicación interna}

Con la reestructuración de la propuesta de valor y el rediseño de los pilares de la experiencia cliente, inicié la etapa de lanzamiento "V1" de la escuela, creando un plan de comunicación interno para concientizar a la comunidad de estudiantes sobre las ventajas del nuevo perfil del egresado y a los pilares académicos y operativos sobre los cuales la escuela se habia reorganizado y dirigi el lanzamiento del nuevo enfoque de la carrera en todos los foros internos de la universidad.

Hasta este momento, la comunicación externa de la escuela se realizaba a través de los canales oficiales de la universidad, administrados por el área de marketing, sin embargo debido a las restricciones de uso de los mismos, muy pronto incorporé, el desarrollo de canales digitales y redes sociales propias de la escuela, libere asimismo la posibilidad de la difusión de proyectos través de las redes de los alumnos (brandeando todas las producciones, entregables, proyectos, concursos, etc), para que todas las producciones y comunicaciones generen un impacto en el awareness de marca, relevante desde la perspectiva de generar motivación en el primer público objetivo (alumnos) y decidido a nivel de frecuencia y influencia sobre los clientes potenciales.

De esta forma la comunicación interna debía ser una herramienta estratégica para lograr el alineamiento de públicos tanto internos (plana docente, administrativa, líderes de bloque, estudiantes) como a nivel de estrategia de marketing para públicos externos y clientes potenciales, para ello base las acciones estratégicas y operativas sobre 3 pilares:

\section{2,b,1 Creación del discurso de la escuela}

El discurso de la escuela se basó en centrar al alumno en el centro, desde la perspectiva de una experiencia usuario satisfactoria basada en el ejercicio profesional desde el primer ciclo, y en la construcción de la evidencia de éxito (CV documentado con todas las competencias desarrolladas a lo largo de 5 años distintos roles y cargos en cada uno de los LDP ) . La comunicación tuvo una orientación hacia el protagonismo de los estudiantes como creadores de su éxito futuro y la forma coherente como todos los procesos de la escuela dirigían al alumno a ser capaz de competir con éxito con cualquier otro alumno de cualquier universidad, ante la comparación de las destrezas desarrolladas, evidenciadas en el book del estudiante y respaldadas por la escuela y la universidad, destrezas que además constituían la prueba del discurso comercial del negocio. 

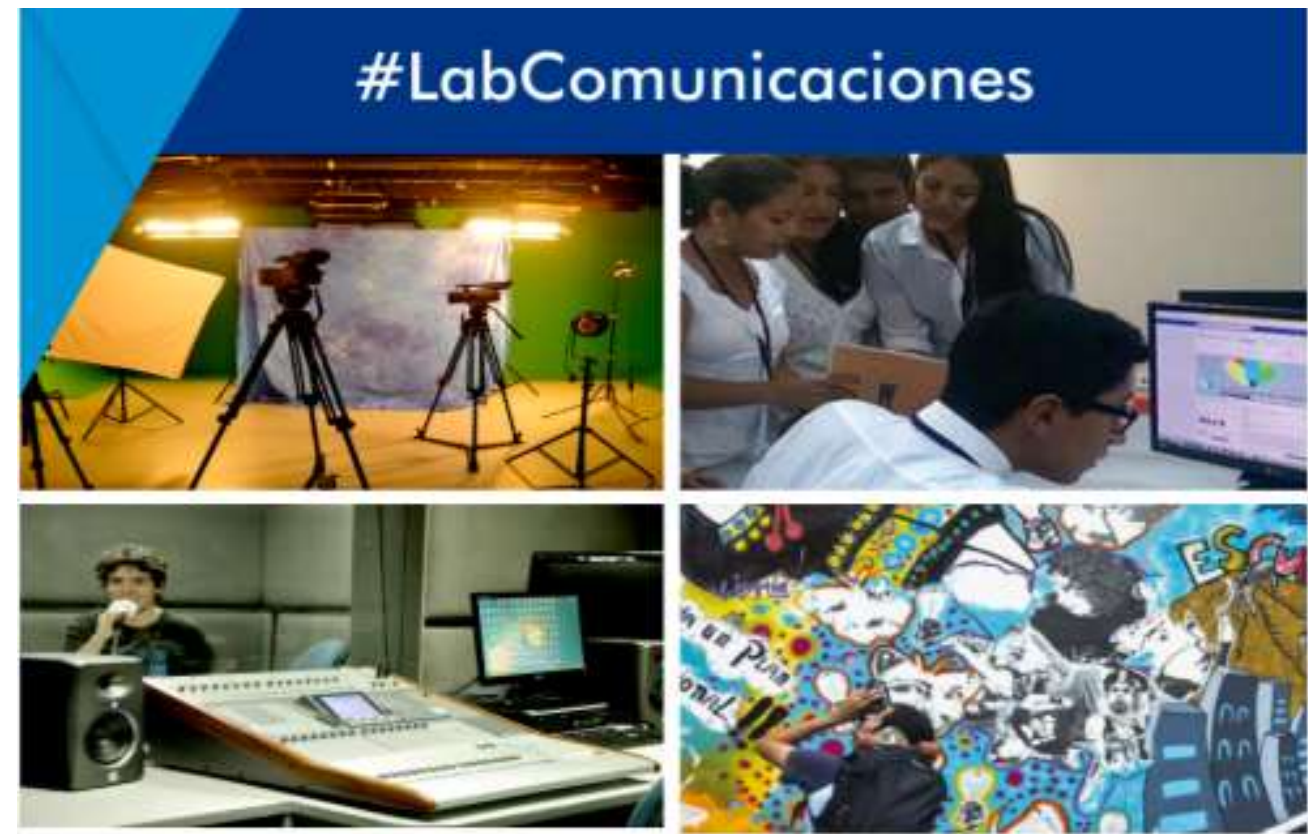

"LABORATORIOS DE DESARROLLO PROFESIONAL"

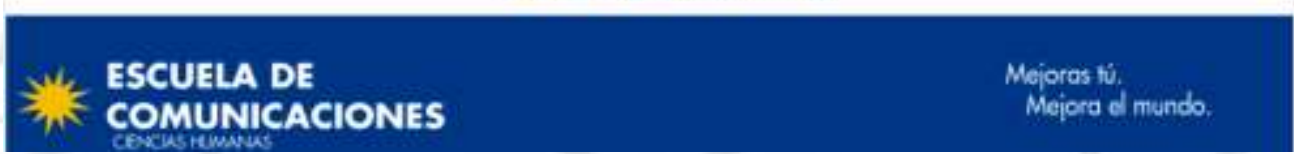

Comunicación interna asociada a la estrategia de creación de los LDP

La creación del profile profesional, fue un elemento que construyo valor y satisfacción en el alumno como respuesta a la forma que los alumnos tenían para competir con éxito en el mercado laboral, frente a los egresados de otras universidades con mayor posicionamiento y tiempo en el mercado. Para ello acuñe la expresión construcción de la "Evidencia de éxito profesional" probando el ejercicio de la carrera profesional desde la universidad" 


\section{PROFILE PROFESIONAL en cada especialidad}

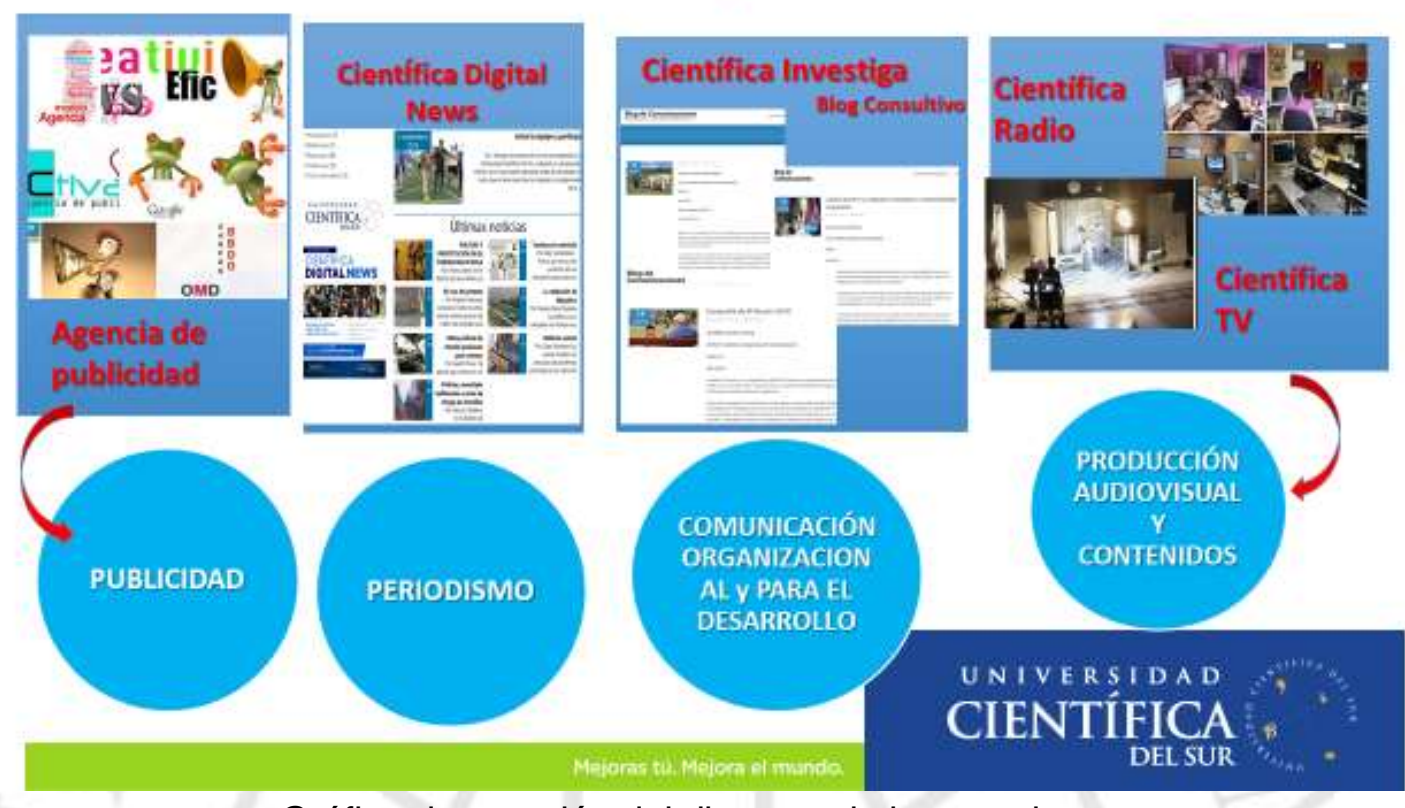

Gráfico de creación del discurso de la escuela

Con este objetivo claro, tanto en presentaciones internas como externas, todas las piezas comunicacionales, programas de tv y radio, publicaciones digitales e impresas, toda la comunicación se orientaba a mostrar la forma alineada como estudiantes y profesores lograban los objetivos del estudiante desde la perspectiva académica, y que se estructuraban como mensajes que impactaban el mercado desde la perspectiva comercial, la escuela se convirtió de esta forma en una productora altamente productiva, capaz de ir de la estrategia al plan operacional y táctico de manera permanente, organizada y validada por la dirección. 


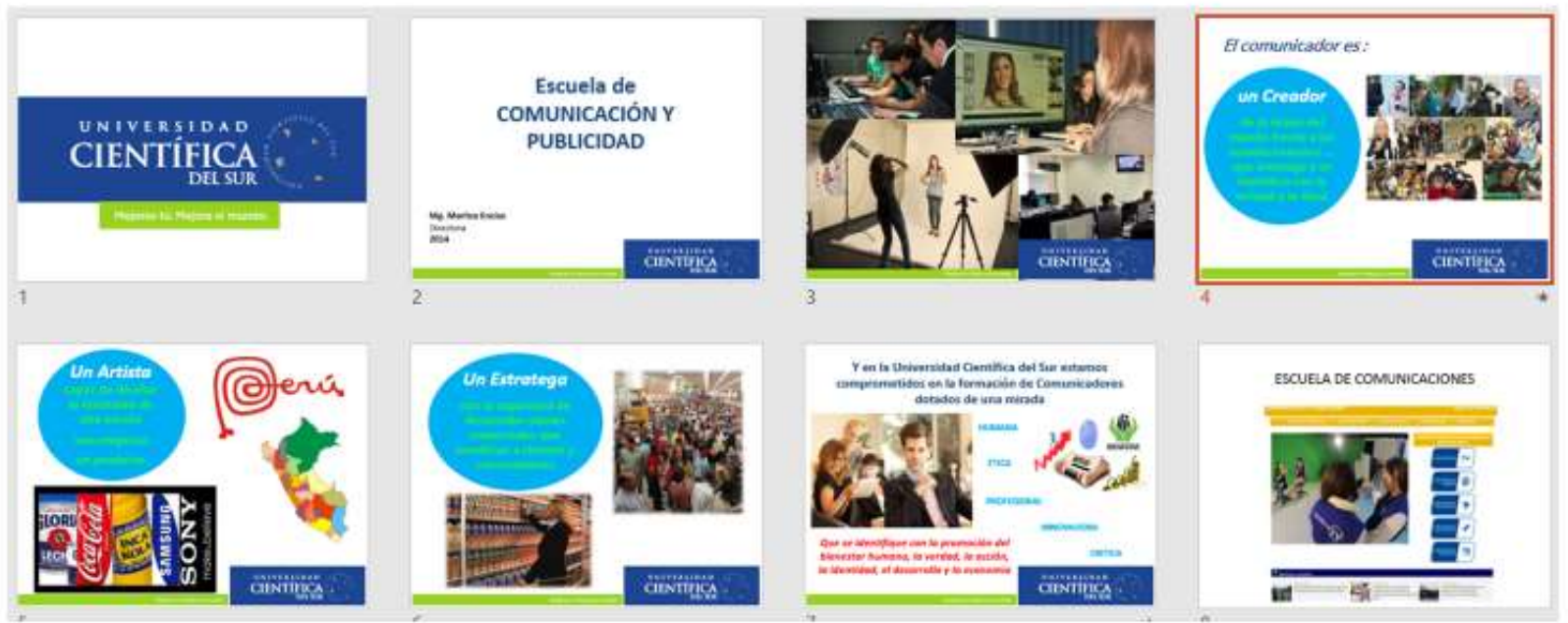

Comunicación Interna. Alineamiento de enfoque. Estudiantes y Docentes
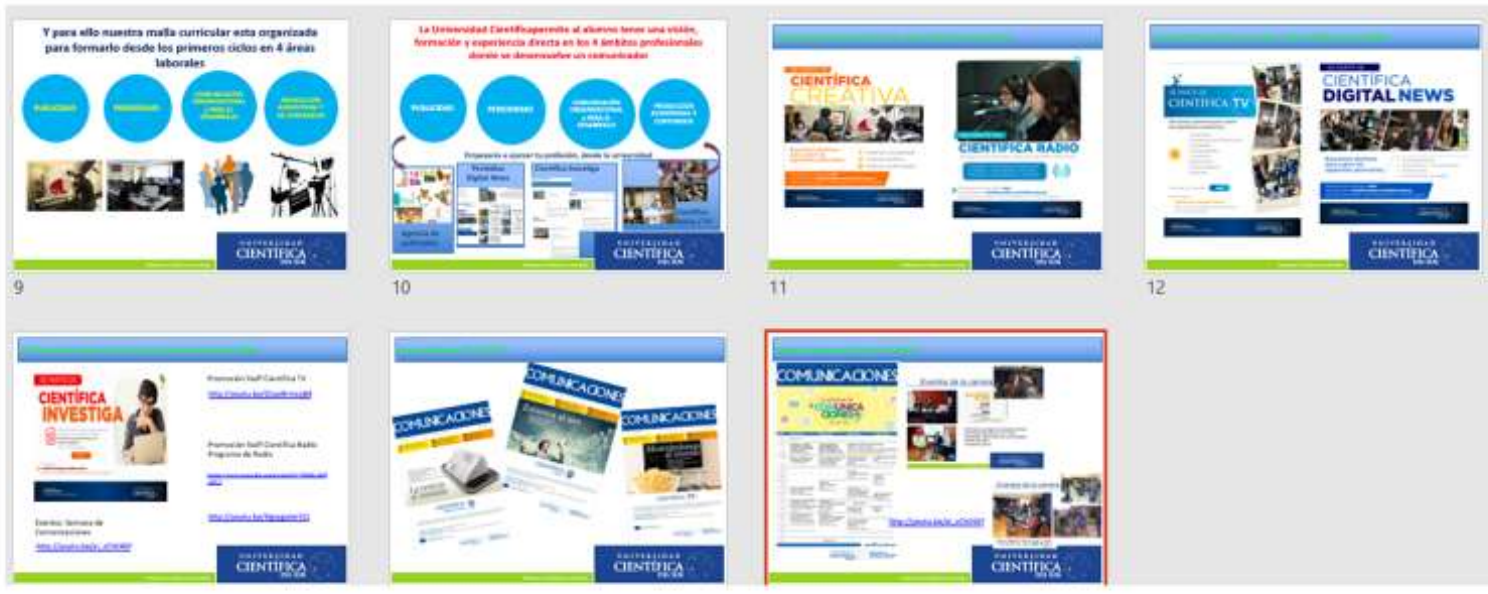

\section{2.b.2. Sistema de Reconocimiento de logros por bloque en cada ciclo}

Como parte de la cultura interna, la escuela desarrollo una política de reconocimiento, tanto de alumnos como del staff de profesores que lograban el cumplimiento de los objetivos semestrales, a nivel de generación de contenido, creación de evidencia de desarrollo de competencias y de proyectos emblemáticos, distinguiendo los mejores proyectos del ciclo, los cuales era divulgados y viralizados en el siguiente ciclo académico, tanto en las redes de la escuela, plataformas de comunicación, como plataformas oficiales de la universidad, incrementando la notoriedad de la escuela en su 
público objetivo y mejorando el sentimiento de identificación y satisfacción con el alma mater, evidenciado en la reducción de la deserción estudiantil.

\section{Comunicación interna: Listados de logros por bloque. Reconocimiento.}

\section{Logros: Bloque Audiovisual: Televisión y Radio}

\author{
Producción de Programas TV: \\ http://urww cientifica edu.pe/carreras \\ Lanzamiento de Programas de Autoría \\ Propia \\ - -Programa "Cientifica al dia" \\ - - Programa "Deli científica" \\ - Programa "Conociendo a \\ - Programa "Dejando huella" \\ - Programa "Desde el Campus" \\ - -Programa "Shot Cultural" \\ Producciones de Programas de Radio: \\ http://wwww.cientifica.edu.pe/carreras \\ - Programas Científica Radio \\ Magazine
}

$$
\begin{aligned}
& \text { - Programas "El cientifico" } \\
& \text { - -Programas "Estamos en el aire" } \\
& \text { - - Programa "Científica sport" }
\end{aligned}
$$

\section{Participación en Concursos a nivel} Nacional:

- Filmación del 1er Cortometraje de la escuela "Reminiscencia" (el cual quedó Finalista en el concurso internacional organizado por Fenace en octubre del 2015)

- Filmación del 2do Cortometraje "Por siempre mia", a estrenarse en marzo 2016

Making of cortometraje: https://www. youtube.com/watch?v=e Dwl w9voig\&feature=youtu,be

\section{Logros: Bloque Comunicación Organizacional:}

Agencia Investiga:

- Se conformó y fortaleció la agencia Investiga, y vienen trabajando en proyectos comunicacionales que aporten en la mejora de la Comunicación organizacional de empresas (Beneficencia Publica de Lima)

Proyectos Comunicacionales:

- Se desarrollo el proyecto "Siembra Esperanza" asociando acciones de Responsabilidad social dentro del bloque organizacional de la escuela

- Se vienen desarrollando el Proyecto de Investigación "Contaminación Visual en las Campañas Electorales".

Blog consultivo:

http://wrww.cientifica.edu.pe/blogs/comunicaciones

- A través de la herramienta web se difundieron trabajos de investigación virtual a reconocidas empresas e instituciones del país Reconocimiento de empresas e instituciones del pais:

A través de Auditorias de Comunicación, empresas privadas e instituciones públicas reconocieron el trabajo de investigación y propuestas estrategicas de los estudiantes:

- Beneficencia Pública de Lima Metropolitana

- ONG "lucha contra la inseguridad ciudadana"

- Embajada de Palestina

Prácticas Pre profesionales:

- 02 estudiantes lograron ser seleccionados por las empresas objeto de estudio luego de la presentación de proyectos comunicacionales.

- Embajada de Palestina (Está en proceso la incorporación de la estudiante)

- Beneficencia Pública de Lima Metropolitana (El estudiante está en ejercicio de actividades)

Organización de eventos:

- Organización del 1er: "Taller de Comunicación organizacional" liderado por estudiantes de la escuela, con la finalidad de difundir y resaltar la importancia de la comunicación a nivel de organizaciones. 


\section{Logros: Bloque Publicidad:}

\section{Científica Creativa:}

- Creación de la agencia de publicidad "in house" con el fin de desarrollar campañas con enfoque social y de actualidad

Creación de Campañas Publicitarias:

- Generación de la primera Campaña "Ciberadicción", difundida y presentada al área de Marketing para su difusión interna y externa

- Campaña de bien público: "Ser +" (actualmente se encuentra en fase de elaboración de piezas gráficas)

\section{Logros: Bloque Periodismo:}

Lanzamiento del periódico digital y conformación del staff de reporteros y periodistas de nuestra escuela Cientifica Digital News

http://digitalnewscientifica.blogspot.pe/

Concurso Nacional

- Participación en el Concurso Nacional de Periodismo "Crecimiento Verde".

Distinciones

- Premios a estudiantes que obtuvieron el 1er, 2 do y $3 e r$ puesto en Concurso Universitario promovido por la Ofic. de Extensión y Proyección Universitaria (categorías Cuento, Poesía, Periodismo literario)

Cada ciclo académico, en la ceremonia de lanzamiento de ciclo, frente a todos los estudiantes matriculados, profesores, lideres y autoridades invitadas, se realizaba la presentación de los resultados de los mejores proyectos del ciclo anterior, se proyectaba las piezas comunicacionales ganadoras, se premiaba a los alumnos con diplomas de competencias alcanzadas, y se generaba un ambiente de logro, distinción y éxito, acorde con los insights identificados en los estudiantes de la escuela, cada uno de estas ceremonias durante casi 4 años sirvieron como discurso de marketing de la escuela, pues fueron concebidos justamente para ello.

\section{2.c. Aseguramiento del nivel de satisfacción del alumno:}

\section{El delivery del servicio.}

El cambio de mindset fue uno de los retos más importantes, a una alta y decidida orientación hacia el cliente en todos los puntos de contacto (Customer Journey Strategy) y al mercado (con la evaluación de competidores, análisis del cliente actual y potencial, transformación del producto, gestión de cambio), fueron las bases para la construcción de una cultura de excelencia en el delivery del servicio.

La reorientación de la estrategia hacia el CUSTOMER INTIMACY, optimizando la relación con el alumno, fue el centro de la estrategia, basada en la ubicación del estudiante en el centro del proceso formativo, para hacerlo protagonista de su formación, intensificando los vínculos de identificación con la escuela.

En paralelo, orienté la estrategia hacia la EFICIENCIA OPERATIVA, con el lanzamiento de una nueva metodología de trabajo docente, decididamente reorientada hacia el enfoque práctico de la carrera en cada uno de los cursos, desde el 1er ciclo hasta el 
10mo cliclo, con una cultura interna asociada al logro de resultados medidos por los KPIs de la performance del docente en la política de construcción de "las evidencias" del desarrollo de las competencias de los estudiantes, participación exitosa en concursos y desarrollo de proyectos emblemáticos, fueron la medida del éxito y reconocimiento del docente, en este sentido la incorporación de KPIs así como un nuevo sistema de supervisión "incógnita", entrevistas y encuestas aleatorias a estudiantes, sentaron las bases para establecer los nuevos estándares de calidad de los procesos educativos y académicos de la escuela, y brindar una retroalimentación docente considerando varias fuentes de información..

Dos funciones principales, la definición de estándares académicos para el aseguramiento de la satisfacción del alumno:

1. Reducir la deserción de estudiantes

2. Incrementar la recomendación y la fidelización. 


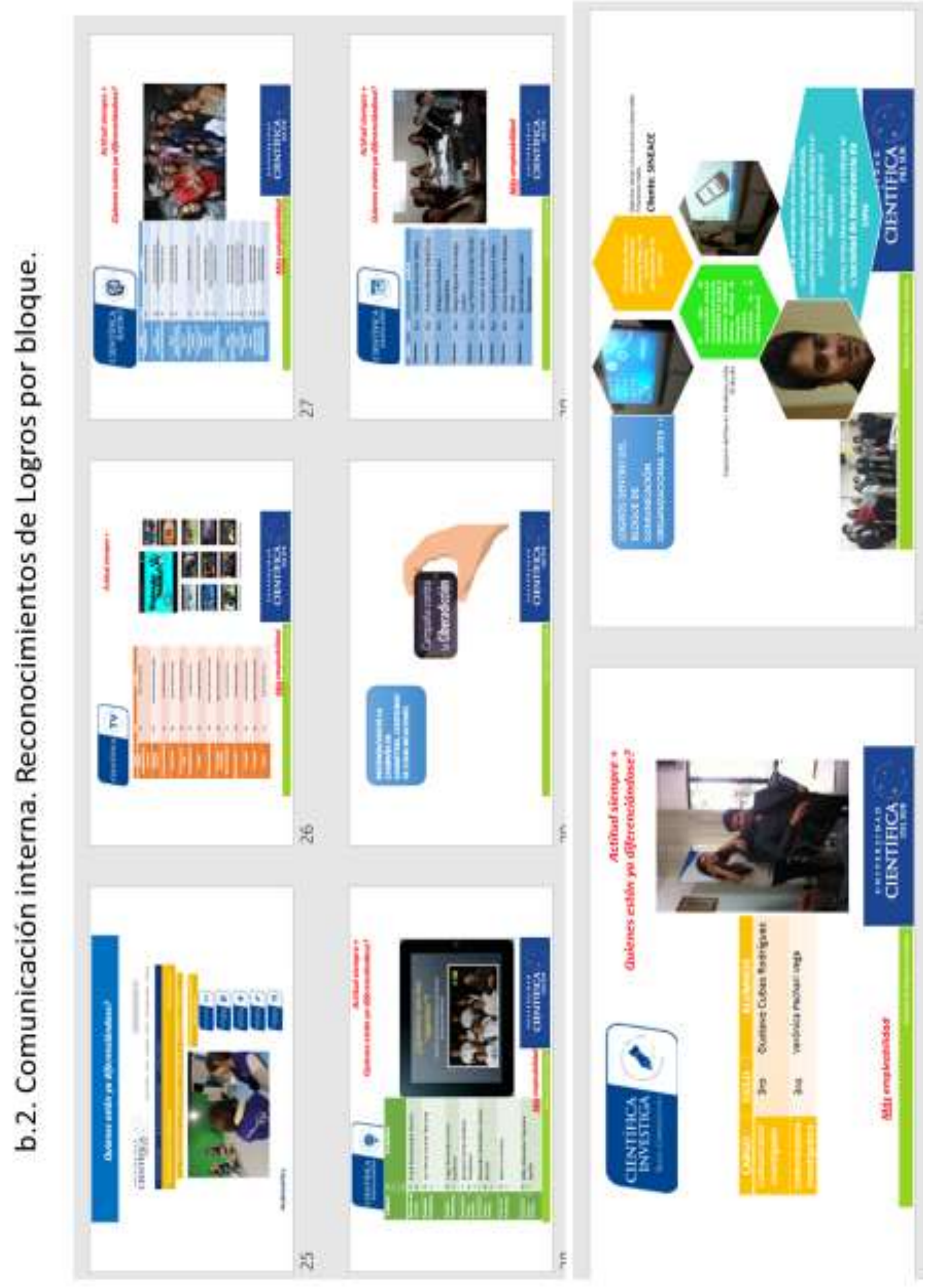




\subsection{Plan de comunicación}

\section{3.a. Posicionamiento de ideas fuerza.}

Construimos 2 ideas fuerza para el posicionamiento competitivo buscado para la escuela : "Vive tu carrera desde la universidad" y "Ejerce tu carrera desde el primer ciclo", los cuales resumían la estrategia de producto sobre la cual se construyó la estrategia de comunicación, evidenciando la alta orientación a la práctica y la aplicabilidad directa en casos y proyectos reales, sobre la base de un plan de estudios renovado y que respondía a los retos laborales actuales.

\section{Objetivo Estratégico 1}

Fortalecimiento del posicionamiento e imagen de marca de la carrera (clientes internos y externo)

\section{Objetivos Específicos:}

1. Consolidar e incrementar las producciones propias de los alumnos (cientifica tv, radio, científica investiga, agencia de publicidad y la nueva científica digital news) con foco en:

1. Viralizarlas para generar notoriedad en el segmento objetivo interno y externo

2. Masificarlas en la comunidad interna (en los espacios públicos). Con producciones radiales cada semana, televisivas cada 15 dias, periodísticas cada semana, organizacionales cada mes.

http://www.cientifica.edu.pe/carreras/cienciashumanas/comunicacion_publicidad.php

http://www.cientifica.edu.pe/blogs/comunicaciones prensa/

2. Participación en 4 concursos nacionales

- Concurso de cortometrajes (2 al año)

- Concurso de periodístico (telefónica)

- Concurso de investigación (Fincyt - concitec)

- Concurso Fotográfico (Sony World Photography Awards

\section{3.a.1. Empleabilidad}

De cara a los objetivos específicos, La construcción de este posicionamiento se soportó en el lanzamiento y operación de los "Laboratorio de Desarrollo Profesional", uno específico para cada uno de los 4 bloques académicos, desde la perspectiva de una universidad capaz de brindar los espacios para la práctica del ejercicio laboral de todos los estudiantes desde el primer ciclo, pero orientado a un objetivo personal concreto: la creación del "Book" de producciones propias que respaldaría el CV del futuro profesional.

Lo interesante desde la perspectiva del estudiante, es que los LDP se orientaban directamente a la construcción de su empleabilidad y al mismo tiempo eran los espacios de interacción universitaria, donde desarrollaban competencias cognitivas, procedimentales y actitudinales propias de cada especialidad y se dinamizaba su aprendizaje, incrementando en conjunto el convencimiento de "vivir la carrera desde el 1er ciclo" entrenando las competencias y habilidades que el mundo laboral demanda. 


\section{En que área comunicacional no estoy desarrollando evidencia de experiencia??}
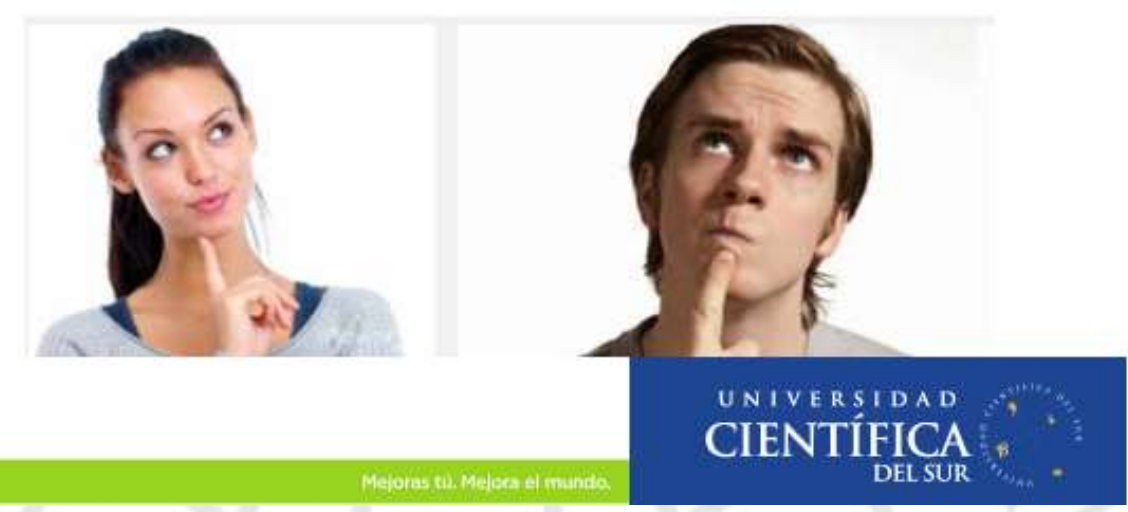

\section{3.a.2. Vivir la carrera desde la universidad:}

La línea de comunicación y de marketing para impulsar el posicionamiento de la escuela se basó en una activa difusión y publicación de los "entregables" que en cada curso, ciclo a ciclo todos los estudiantes producían, segmentando a los clientes potenciales tanto por zona geográfica de influencia de la universidad (distrito de chorrillos, villa el salvador, lurin, surco, barranco, villa maría, sjm, según arrojo el análisis de los datos de procedencia de los alumnos en los últimos 3 años), también se uso segmentación por grupos de interés (comunidad de publicidad, periodismo, comunicadores sociales, producción audiovisual, dirigiendo un speech y publicaciones específicos para cada publico), por otro lado se creo una comunidad de seguidores de redes, donde eran los alumnos directamente quienes invitaban a sus amigos y familiares a ser parte de las redes de la escuela, creando así un círculo proactivo de influencia asociada a la actividad académica (comercial) de la escuela, considerando que los mismo alumnos trabajaban durante todo el ciclo para la generación de contenidos comunicacionales los cuales, siendo productos académicos eran al mismo tiempo argumentos de venta y de posicionamiento en todos los canales de contacto con la comunidad y postulantes. Para asegurar el dinamismo y presencia en redes, además de la creación de las comunidades mencionadas, se sincronizaron campañas de difusión del mundo digital y mundo real, logrando hacer contundencia del mensaje dentro de la misma universidad, "antes", "durante" y "después" de cada comunicación y actuación de la escuela. 
PROTECTOR DE PANTALLA

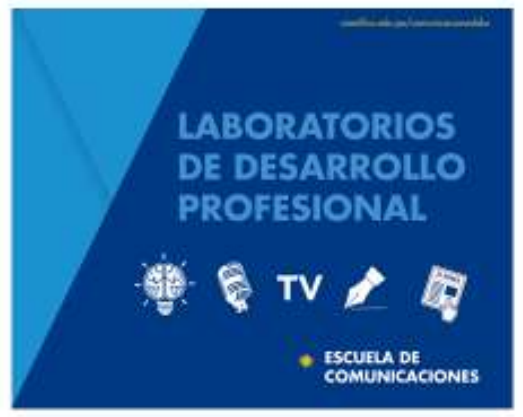

El protector sale mientras la computadora está en

descanso. Cuando se mueve el mouse, sale el fondo de pantalla

PJ-203

PJ-208

PJ -209

$\mathrm{PI}-202$

PI-101
Salas de Estudios

Villa 02 : PJ108

Villa 01 : Biblioteca.
FONDO DE PANTALLA

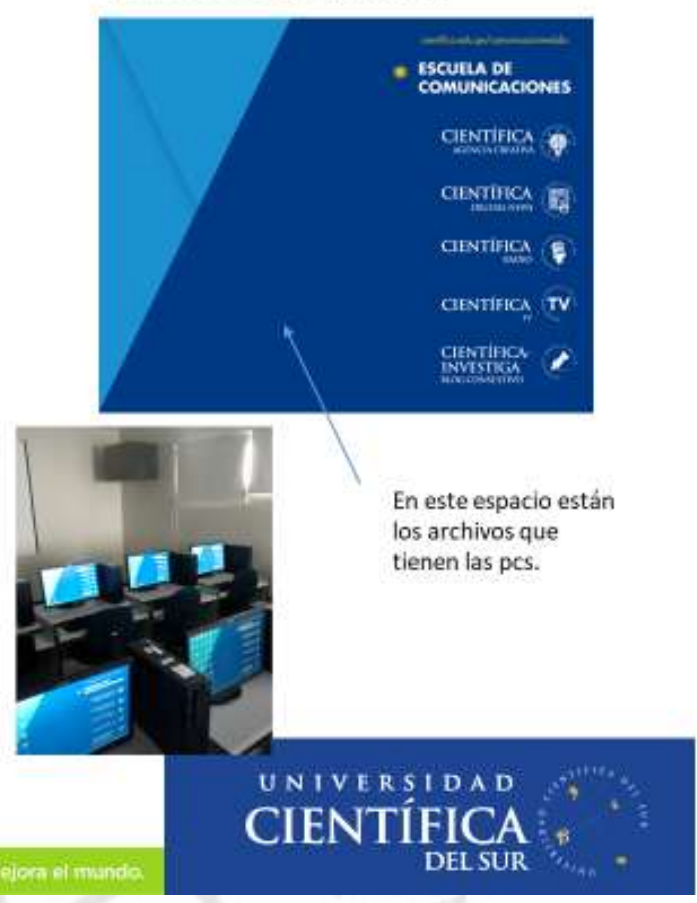

\section{3.a.3. Contacto con la industria y aplicación directa en el mundo laboral:}

Otra idea fuerza utilizada para incrementar la percepción de valor del servicio y reforzar la comunicación del posicionamiento de la escuela, fue el alto nivel de relacionamiento con profesionales y empresas de comunicaciones, gracias a la incorporación activa de profesionales (docentes invitados, ejecutivos emblemáticos, etc) ya sea como expositores de charlas, jurados de sustentaciones de trabajos, clientes que solicitaban el desarrollo de un proyecto, o líderes consultores de soporte en la producción de los programas de radio, tv, prensa, etc, evaluando visiblemente desde las parrillas de programación hasta la metodología de producción de los LDP, impulsando así el desarrollo de entregables y proyectos endosando su prestigio a las actividades de la escuela.

En este contexto cree algunos productos de visibilidad y comunicación como "La semana de comunicaciones", "La feria de emprendedores", que reunían las 3 ideas fuerza que daban soporte al posicionamiento buscado para la escuela, asociado a los insights identificados en los estudias de la científica:

- Posicionamiento basado en la visibilización de los logros de los alumnos

- Posicionamiento basado en conexión de la escuela con la industria de las comunicaciones a través de la presencia permanente de personalidades influyentes.

- Posicionamiento basado en el impulso de los estudiantes para desarrollar proyectos emprendedores, proporcionándoles espacios para generar ingresos en cada semestre.

Un elemento adicional, fue el número reducido de alumnos, que trabaje como una ventaja competitiva de la escuela, donde a diferencia de otras universidades, los 
alumnos de la escuela, gozaban de la disponibilidad y atención permanente y directa de profesores, coordinadores y dirección.

A nivel del plan de comunicación interno y externo, se activaron todos los canales de difusión, lo cual represento para los alumnos la posibilidad de iniciar la construcción de su reputación profesional respaldada por su alma mater, CIENTIFICA RADIO, CIENTIFICA TV, CIENTIFICA DIGITAL NEWS, CIENTIFICA MAGAZINE, tenían como misión la promoción y emisión de los programas (productos comunicacionales estudiantiles), organizados en parrillas de programación actualizados permanentemente, asimismo la agenca CIENTIFICA CREATIVA desarrollaba las piezas promocionales utilizadas en las redes sociales de la escuela y la universidad.

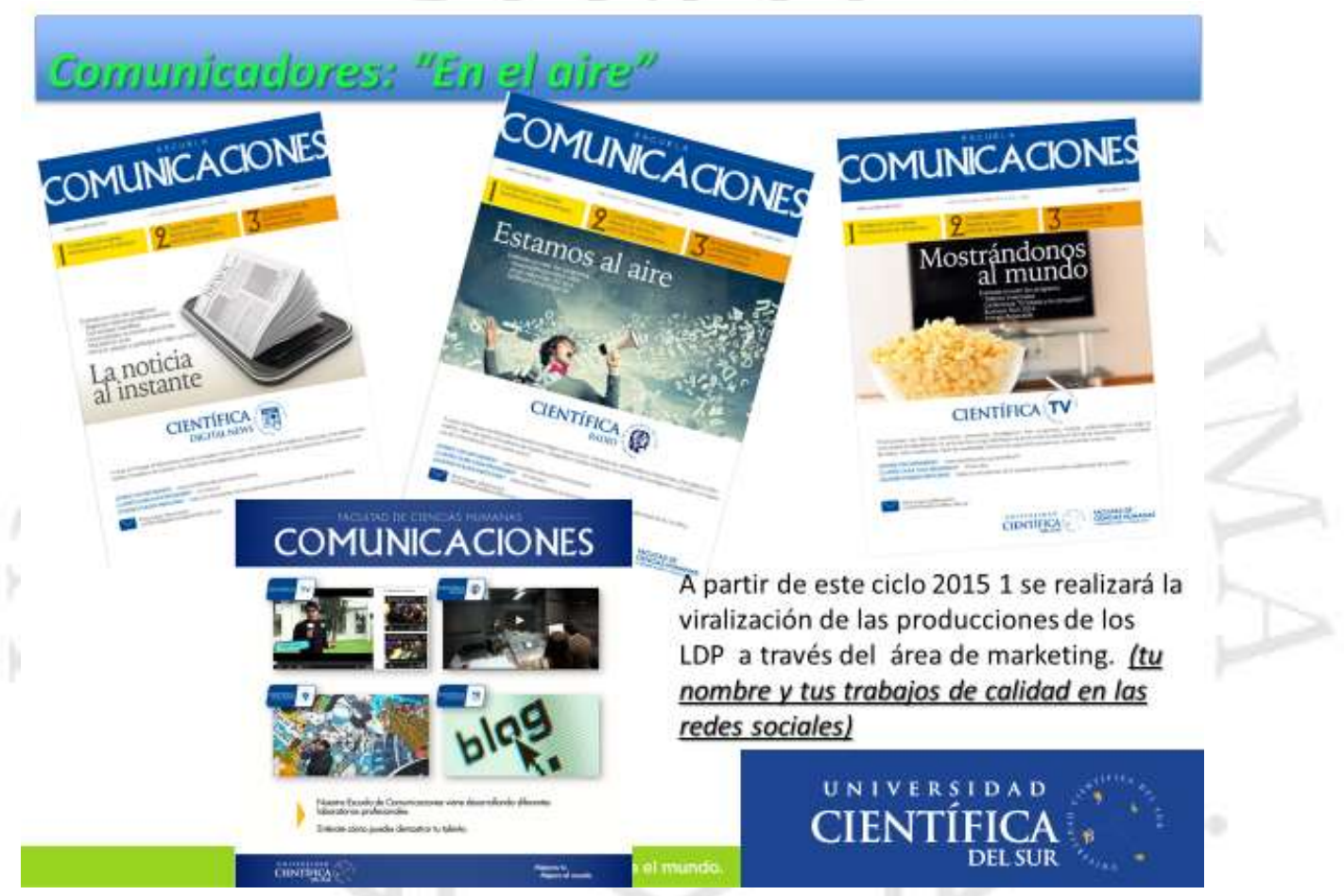

Uno de mis mayores desafíos en este punto fue incorporar en el área de marketing el uso de las producciones y proyectos de los alumnos como parte del discurso de venta, la orientación practica de la carrera, la evidencia del ejercicio de la carrera desde los primeros ciclos, la existencia de laboratorios de desarrollo profesional, el funcionamiento de los 5 LDP; en el tiempo, el peso de los resultados a nivel del incremento de la comunidad de seguidores de nuestras redes sociales propias, evidenciaron que la estrategia era la correcta, la viralización de los logros de los estudiantes de todos los ciclos, había atraído mucho más que las estrategias BTL que tradicionalmente se realizaban (open campus, tour guiado, etc)

\section{3.b. Creación de en las plataformas de comunicación de la escuela}

La estrategia de "entregables" fue la base para la generación de contenidos sobre la cual se basó la estrategia de comunicación de la escuela, convocando y alineando tanto a 
estudiantes como al staff, orientados todos a generar un discurso activo de la marca, que potenció la satisfacción de los estudiantes. Asimismo, las plataformas de difusión de entregables, proyectos, concursos, comunicaciones internas y externas, estaban ya definidas en la creación misma de los LDP.

Cada uno de los LDP, fue un medio de comunicación para la escuela, una plataforma de marketing interno y externo. En este punto la escuela ya trabajaba orientada a generar permanentemente contenidos y difundirlos en las plataformas de comunicación propias.

En términos de estrategia comercial, dirigí el diseño de la imagen visual de cada uno, logotipos e identidad gráfica, lanzando entonces oficialmente los medios de comunicación digitales masivos de la escuela de comunicaciones, creando activos intangibles que incrementaron el valor de la marca y fueron registrados a nombre de la universidad como propietaria de sus denominaciones, todas ellas creadas por mi, en mi gestión como directora de la escuela.

\section{3.b.1. Canal de TV : CIENTIFICA TV}

Canal en Youtube, con contenido on demand y en vivo. El canal logro reunir a una comunidad de más de 5000 seguidores, ofreciendo nuevas producciones semanalmente, en programas elaboradorados por alumnos, quienes debian presentar un plan de producción de 6 programas durante 1 ciclo de estudios, considerando en el equipo de producción a alumnos desde el primer ciclo, asignándoseles tareas en la que estuvieran en total capacidad de aportar y aprender, seleccionados por la dirección de la escuela y coordinados por los líderes y profesores de curso. La parrilla de programación tenía una duración de 4 horas diarias de programación.

\section{3.b.2. Radio Online y on demand: CIENTIFICA RADIO}

Antes de mi incorporación como Directora, el curso de realización radial, permitía la practica en la cabina de Radio de los estudiantes y la grabación de programas radiales que podían ser escuchados por internet. a la cual se accedía inicialmente a través de un enlace a internet, NO existía un plan estratégico para explorar el uso de este potente medio frente a todas las posibilidades de una escuela de comunicaciones. Luego de mi ingreso, el uso académico de la cabina de radio, cambio radicalmente y desde el formato que cambio a RADIO-TV, con el objetivo de mostrar a los estudiantes de la universidad, produciendo y transmitiendo al aire programas de radio, mensajes publicitarios, cuñas de la escuela, entrevistas, etc, se potenció su presencia y demanda a través de la promoción del logo-icono de la radio, el cual se podía bajar al celular, o desde un computador para escuchar la programación diaria de 4 horas en vivo. Este formato, permitió la transmisión de publicidad sonora creada por el bloque de publicidad e integró en su programación las publicaciones del bloque de comunicación organizacional en formato entrevistas.

\section{3.b.3. Revista impresa: CIENTIFICA MAGAZINE}

Con un tiraje de 2000 ejemplares anuales, y un prepuesto mínimo, la revista impresa tenia como objetivo llegar a postulantes y estudiantes de comunicación e identificar a los 
estudiantes de todos los ciclos de la carrera, participantes a través de diferentes cargos en la revista, ejerciendo su carrera desde las aulas. La revista fue utilizada como medio de promoción en todos los open campus de la escuela. Este medio fue el primero en ser considerado como el piloto para convertirlo en una "unidad productiva" de la escuela, con la venta de publicidad para clientes reales, los cuales inicialmente serían los negocios proveedores de servicios estudiantiles dentro del campus, y luego clientes externos que por zona de influencia ofrecerían sus servicios y promociones en la revista de la escuela.

\section{3.b.4. Periódico digital: CIENTIFICA DIGITAL NEWS}

Periódico en formato digital, actualizado diariamente por los alumnos de los primeros ciclos de la universidad, en el las informaciones mas relevantes, sociales y coyunturales eran parafraseados citando las fuentes y siendo supervisados por lideres y profesores de los primeros ciclos. Este medio tuvo uno de los retos mas demandantes frente a los demás medios, debido a la actualización diaria, sin embargo esta característica y dinamismo, contribuyo al logro del objetivo de fidelizar tempranamente a los estudiantes de los 1ros ciclos, de mayor riesgo a nivel de deserción, en torno a proyectos de la escuela, desde el inicio de sus estudios, en un momento de la carrera donde la creación de vínculos con otros estudiantes, sentido de pertenencia y ansiedad por la confirmación de una buena decisión en términos de la selección del alma mater, son variables que deben controlarse decididamente.

\section{3.b.5. Blog: CIENTIFICA CONSULTIVA}

Asi como el laboratorio de publicidad se ocupó de la creación de campañas de publicidad internas y externas para CIENTIFICA RADIO, el BLOG de comunicación organizacional, contribuía permanentemente a la creación de contenido para la revista impresa, digital, programas de radio y programas de tv. Su plan de trabajo creció en el tiempo y de ser un blog orientado a brindar soluciones a casuística de comunicación empresarial y social, se convirtió luego en CIENTIFICA INVESTIGA, laboratorio orientado a la ejecución de proyectos de auditoria en comunicación organizacional para clientes reales, ese fue su desafío, solo desarrollaba proyectos por encargo. El logro más importante de este laboratorio fue convertirse en una plataforma de visibilidad para los estudiantes a cargo de los proyectos, varios de los cuales fueron contratados, por las instituciones solicitantes de los proyectos.

\section{3.b.6. Agencia de publicidad: CIENTIFICA CREATIVA}

La creación de esta agencia de publicidad respondió inicialmente al desarrollo de campañas publicitarias de productos ficticios, paso luego a productos reales, encargos de la dirección y generación de campañas de concientización por encargo del área de marketing de la universidad.

La agencia, a través de sus integrantes desempeñando todos los roles y puestos reales de una agencia en el mercado, desarrollo un dinamismo propio que la llevo a 
desarrollar publicidad para la radio, cuñas de la escuela, promociones de los programas de tv. Posteriormente encargue a la agencia el reto de desarrollar programas de TV dedicados a desarrollar temas de publicidad en formatos de 30 a 40 segundos. La agencia desarrollo rápidamente sus competencias y fue la primera en estar lista para lanzarse a la búsqueda de clientes fuera de la universidad, desarrollaron para ello su identidad gráfica, crearon su propia web, presentación corporativa dinámica.

La creación y dirección de esta agencia de publicidad dentro de la universidad, fue un gran reto principalmente en términos de la demanda de espacio para la creación y contribución a los objetivos de la escuela y de la universidad que los jóvenes publicistas, en formación, mostraban estar en capacidad de asumir...

Para mí como Directora, la creación y operación de cada una de estas plataformas de comunicación, significo la consolidación de la mística de los estudiantes de comunicación de la científica, que aprendieron a lograr resultados, con pocos recursos, enfrentando la medida de los desafíos del mercado, administrando tiempo, gestionando expectativas, cumpliendo plazos, enfrentándose a la crítica, manteniéndose enfocados en el logro de objetivos, como los profesionales en ejercicio estamos acostumbrados a trabajar.

Todas estas plataformas funcionaron como medios de comunicación de la escuela de comunicaciones, bajo la dirección de la escuela y, respetando los lineamiento generales de identidad gráfica y visual de la marca universidad científica, construyeron la identidad de la escuela, abrieron espacio para que se exprese la comunidad de comunicadores de la científica y permitieron ampliar el impacto de la escuela en sus públicos, contribuyendo al construir un posicionamiento asociado a la acción e incrementar el awareness de la escuela, que pronto se evidenció en el crecimiento del volumen de postulantes, en la mejora de los índices de satisfacción de estudiantes, en el incremento de la recomendación de marca, en la reducción de la deserción y en la mejora del clima de la escuela y la identidad estudiantil.

\section{3.c Comunicación Externa:}

Lideré el desarrollo de la estrategia de comunicación externa, tanto gráfica, como de generación de contenidos, orientada a responder a los objetivos de incremento del número de postulantes, dirigiendo la construcción del plan de marketing y difusión con el área de marketing. Aseguré de esta forma, que el discurso externo se basara en la difusión de los nuevos argumentos de mercado construídos en la propuesta de valor que incorporaba elementos competitivos y diferenciales, en el valor de los nuevos procesos de la experiencia usuario, la construcción de las plataformas permanentes académicas y la organización de la escuela en torno a la construcción de la imagen activa de la escuela; ante la evidencia del poder y la estrategia construida en la escuela, la comunicación externa fue extendida y replicada en las plataformas de comunicación de la universidad dirigidas por el área de marketing (asignando presupuestos para compra programática en redes) y esta sinergia complementó de manera contundente el esfuerzo que, al interno, la escuela ya había iniciado. 


\section{3.c.1 La estrategia de difusión.}

\section{El Relanzamiento de la escuela de comunicaciones y sus LDP}

El plan de comunicación externa que diseñé, convocó al área de marketing para hacer impacto en la comunidad universitaria y en los públicos externos, basado en el relanzamiento de la escuela, las nuevas plataformas CIENTIFICA TV, CIENTIFICA RADIO, CIENTIFICA CREATIVA, CIENTIFICA INVESTIGA, CIENTIFICA DIGITAL NEWS, CIENTIFICA MAGAZINE, definiéndose a la comunidad universitaria como primer público objetivo, donde aulas, salas de estudio, computadores en toda la universidad, incluida el area administrativa, fueron espacios de promoción y difusión de la nueva estrategia académica-comercial de la escuela.

Asimismo, la difusión del valor de la creación de las nuevas plataformas de comunicación de la escuela en los medios oficiales de la universidad y de los contenidos generados en ellos, empezaron a ser parte de la estrategia de marketing y venta de la carrera, los productos elaborados por los alumnos de los diferentes ciclos, empezaron a ser utilizados en las áreas comerciales tanto en presentaciones en colegios, actividades BTL, Open Campus, etc, y si bien su uso fue masivo, el impacto real estaba en tono del mensaje, menos "de agencia" y más de "experiencia-usuario", más story telling de alumnos viviendo la carrera desde el 1er ciclo.

Una vez logrados los primeros programas de tv, radio, etc, organicé, con el área de marketing, las campañas de difusión de contenidos, antes, durante y después de los procesos de admisión y en cada evento interno y externo donde se generara un boca oído directo respecto a la nueva escuela de comunicación de la científica. 


\section{CAMPAÑADE DIFUSION DE CONTENIDOS \\ DE LOS LABORATORIOS DE DESARROLLO PROFESIONAL}

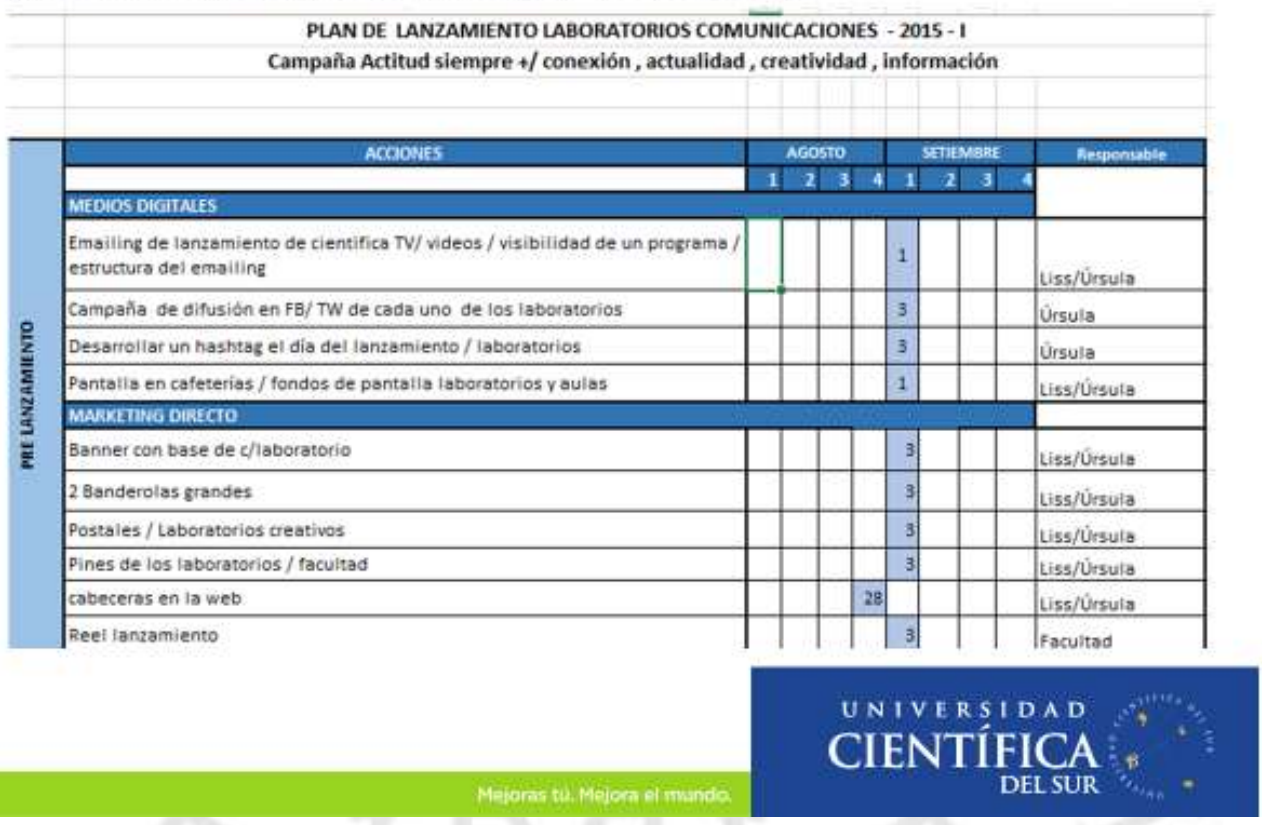

Cronograma de Lanzamiento oficial de los LDP en el Landing Page de la Universidad

\section{Emailing - Landing page}

\begin{tabular}{l|l|}
\hline \multicolumn{1}{c|}{ Piezas } & \multicolumn{1}{c|}{ Fechas } \\
\hline HTML General-Laboratorios & 2 de setiembre \\
\hline HTML- Laboratorio de Agencia Creativa & 7 de setiembre \\
\hline HTML- Laboratorio de Cientifica Radio & \\
\hline HTML- Laboratorio de Cientifica TV & 10 de setiembre \\
\hline HTML- Laboratorio de Digital News & 14 de setiembre \\
\hline HMTL- Cientifica Investiga-Blog Consultivo & 17 de setiembre \\
\hline
\end{tabular}

\section{Promoción de los LDP en la Web de la universidad}




\section{BANNER WEB}

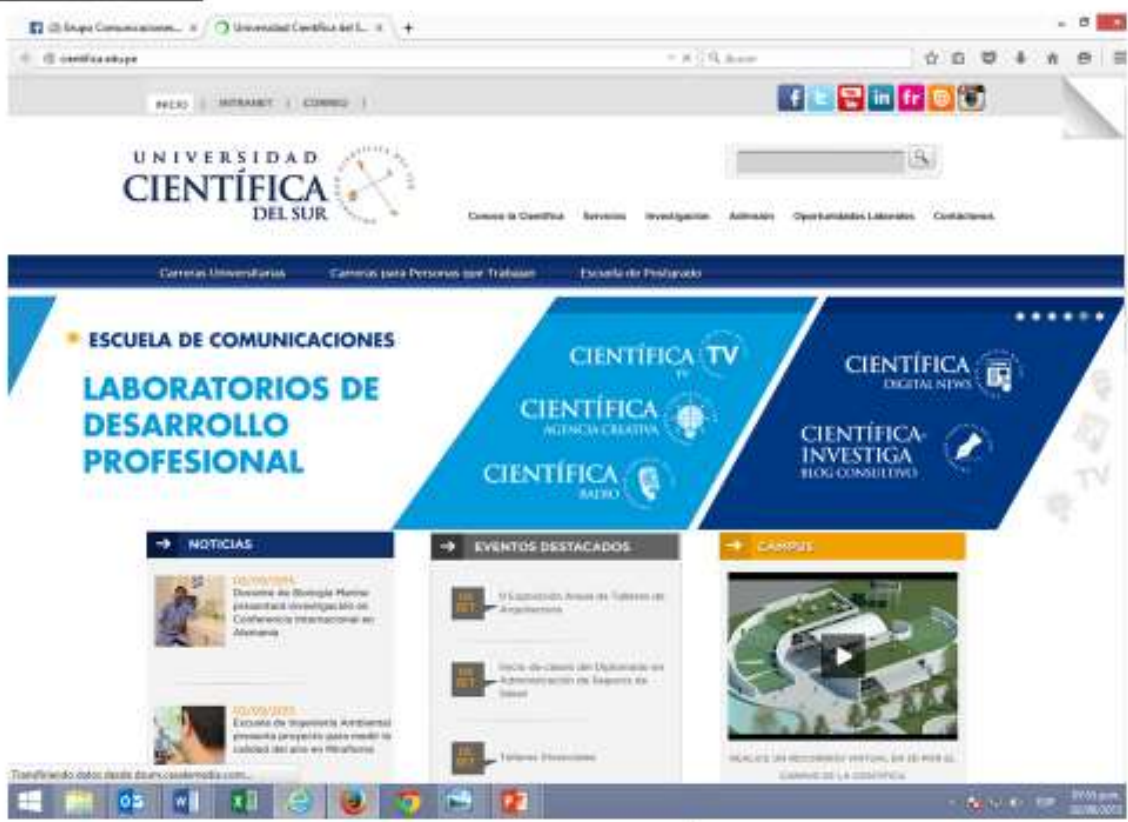

UN IVERS I DA D

CIENTÍFICA :

\section{Cambio del speech comercial de la escuela}

Antes asociado a convenios, infraestructura y campus, hacia un discurso orientado a la práctica de la carrera, ejercicio profesional y la capacidad de una formación profesional que respondía a los insights del consumidor.

CAMPAÑA DE DIFUSION DE CONTENIDOS

DE LOSLABORATORIOS DE DESARROLLO PROFESIONAL

La Escuela de Comunicaciones presenta los Laboratorios Desarrollo Profesional creados para producir contenidos comunicacionales, audiovisuale s, periodisticos, publicitarios y oganizacionales, a través de formatos innovadores creados, dírigidos y realizados

directamente por los alumnos de la escuela, de esta forma los alumnos tienen acercamiento anticipado a su carrera desde los primeros ciclos y construyen tempranamente un portafolio profesional con el cual se distinguirán en el mercado laboral y obtendrán mayores posibilidades de éxito.

Los invitamos a conocer las producciones elaboradas por nuestros alumnos.

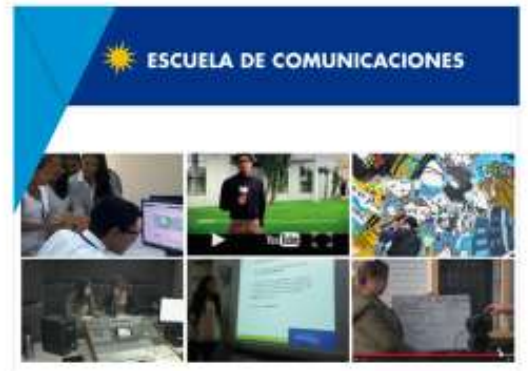

"LABORATORIOS DE DESARROLLO PROFESIONAL"

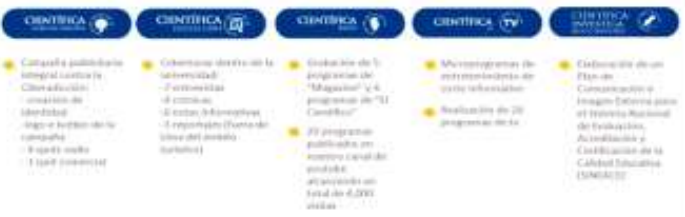

UNAYIMSTDAD CIENTIFICA
Mejoras tú.

Mejora di mundo 


\section{Piezas de comunicación externa utilizadas en redes sociales de la universidad}

Facebook de la Universidad y Difusión en la Comunidad Universitaria

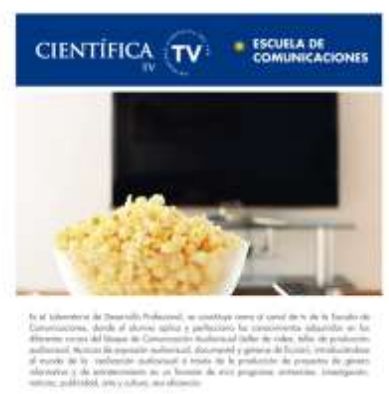

MaA NUESTRA PROGRAMACION WESTr:

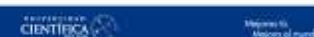

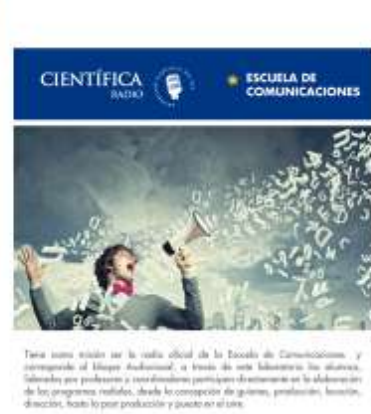

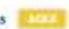
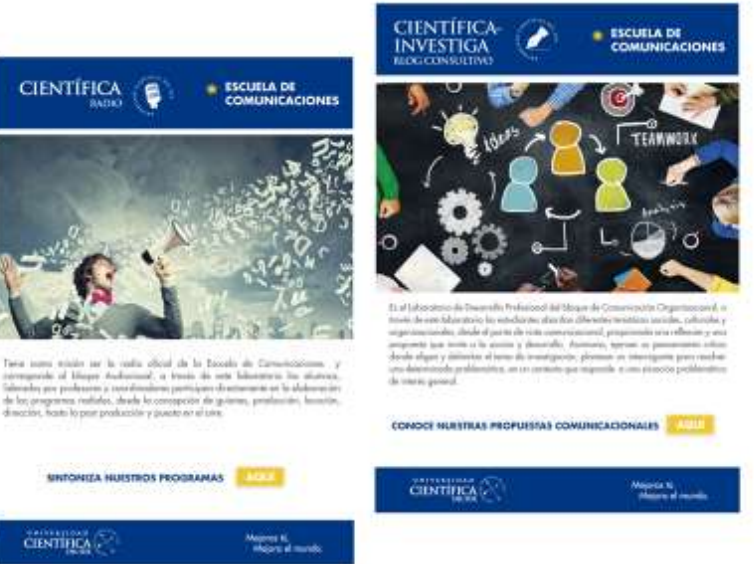

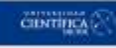

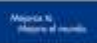

\section{UNIVERSIDAD \\ CIENTÍFICA :}

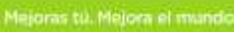

\section{Banners utilizados en eventos de la universidad fuera del campus,}

Difusión en el Campus: Banners
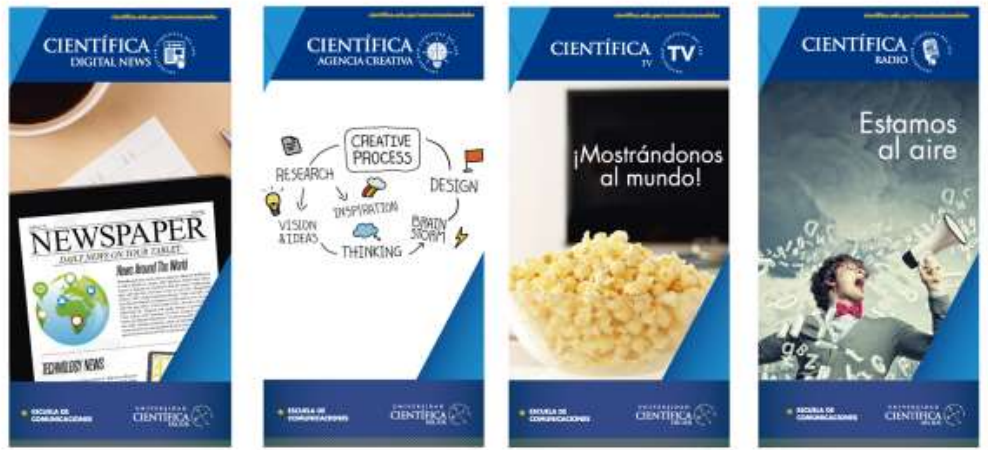

\section{UNIVERSIDAD \\ CIENTIFICA : \\ DELSUR}




\section{Banderolas promocionales del re-lanzamiento de la escuela de comunicaciones.}

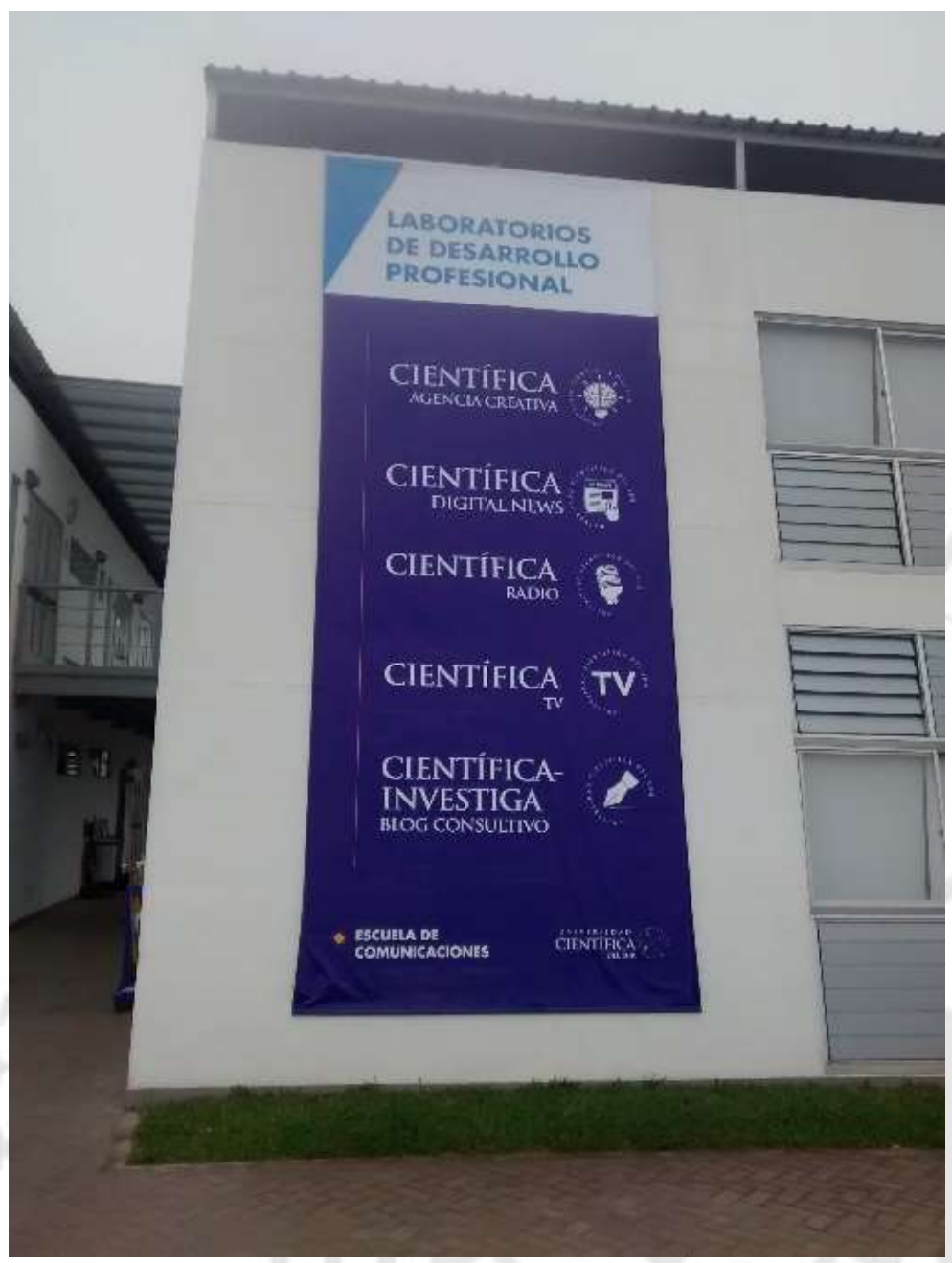

\section{3.c.2. Creación de perfil público oficial de la escuela:}

Con la aprobación de la creación del perfil público de la escuela, se generó un sentimiento de identidad y satisfacción de estudiantes, y con la difusión ya abierta y organizada de la estrategia académico-comercial y logros de la escuela, alumnos, docentes, líderes y coordinadores consolidaron su sentido de pertenencia y valoración de pertenecer a la escuela de comunicaciones de la científica. Se había logrado el nacimiento de una nueva generación de alumnos, activos y protagonistas de la construcción de su futuro, buscando pertenecer a los proyectos y concursos, buscando ser parte de los laboratorios, postulando a los puestos de "trabajo" dentro de ellos, solicitando sus certificaciones de competencias logradas, compartiendo publicaciones, invitando a amigos y familiares a las redes de la escuela, generando nuevos proyectos para cada bloque de especialización y buscando completar no solo 1 sino incluso las 4 especializaciones. 


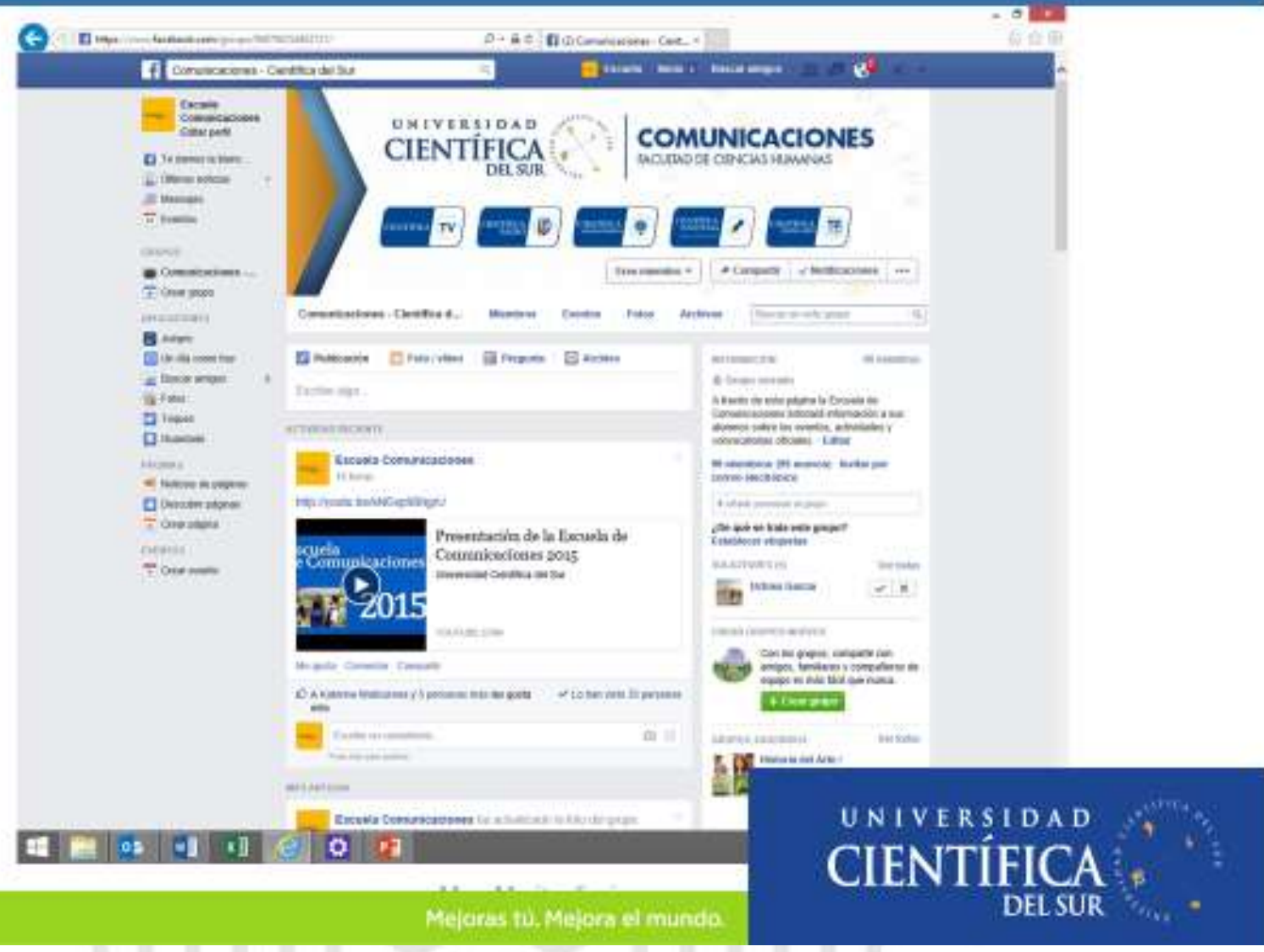

A lo largo de los años de mi gestión y con la mayor especialización y expertise ganados tanto por los equipos de trabajo como por la mística de generación de evidencias de éxito tanto en alumnos como staff de profesores, mi labor se concentraba en acelerar las mejoras y optimizar los procesos que permitieran seguir incrementando el awareness de la marca y su presencia en todos los canales usados por clientes potenciales y stakeholders.

En los siguientes niveles de la estrategia, la creación de unidades de negocio dentro de la escuela, con marcas registradas, Ruc, portafolio de servicios y pricing, brindo un visión desafiante y motivante en toda la escuela, desde la perspectiva empresarial y académica, este camino nos orientaría hacia el encuentro entre la academia y el mercado, entre la perspectiva de autoridad de conocimiento (universidad) y la capacidad de desarrollar investigación aplicada a la generación de soluciones de problemáticas reales del sector productivo. Acaso no es esta visión la que demanda, reclama y entiende como necesidad, la sociedad y la universidad simultáneamente? Solo se requiere un liderazgo simultáneo entre lo académico y lo comercial, experiencia gerencial y experiencia académica completamentaria, pensamiento disruptivo y estratégico orientado a la creación de nuevas formas de llegar al mercado para lograr el crecimiento del negocio por encima de las variables tradicionales de la industria, en otro escenario donde nos alejemos de la competencia, donde ya no sigamos compitiendo dentro del mismo "océano rojo". 


\section{REFLEXIONES PROFESIONALES}

Haber escogido a las comunicaciones como carrera base ha tenido 2 impactos importantes en mi camino profesional.

El primero de ellos es que siempre el cliente, el usuario, el público ha estado en el centro de la estrategia, del producto o servicio, de las acciones y decisiones que hicieran impacto e influencia en el., hoy a la luz de la Innovación corporativa como filosofía de management, donde el "User Design center" es el nuevo reto empresarial, donde hablar el lenguaje del cliente, conocer a fondo y "empatizar" con sus necesidades (hoy insights), preguntar y testear con el cliente; para mi, más allá del uso de nuevas herramientas para asegurar mejores resultados, el tema siempre ha sido más que evidente, y las decisiones estratégicas, operativas y tácticas que he tomado, las he reflexionado y ejecutado desde esa perspectiva, la cual incorporé en las aulas de la universidad.

El segundo impacto, fue la temprana convicción de necesitar basar mis decisiones utilizando KPIS, metodologías de medición y proyección, entender las herramientas de costeo y gestión financiera para corresponder en una toma de decisiones alineada con los resultados que al final de la línea indican a la empresa que los objetivos se han logrado o no. Este fue un aprendizaje que incorporé en mi ejercicio profesional y que me impulsa a planificar y asegurar resultados en términos del directorio empresarial.

Además, con la presión de la tecnología, el surgimiento de "clientes activos" en todas las industrias, las nuevas plataformas de comunicación, que en realidad son de interacción y big data; el diseño de las estrategias de comunicación más efectivas se han enriquecido ampliamente, incorporando al análisis de la psicología del consumidor, la analítica descriptiva y predictiva de datos, permitiendo proponer modelos de "personalización masiva", desde la perspectiva de la omnicanalidad y del autoservicio, como nuevos posibilidades de rentabilizar la experiencia-cliente. Con la incorporación de estas reflexiones, herramientas y metodologías, creo que el comunicador, formado en una universidad, encuentro campo acción en el diseño de la nueva estrategia del negocio, en la capacidad de respuesta a las preguntas del directorio para el logro de los objetivos empresariales.

Al margen de las reflexiones indicadas, me permito finalmente, brindar 3 recomendaciones profesionales:

1. Entrenar el pensamiento crítico y orgánico en la definición de soluciones empresariales, las cuales deben responder a problemáticas de negocio, no solo al área de las comunicaciones.

2. Incorporar en sus saberes profesionales el manejo de herramientas contables, financieras y de medición (métricas y kpis) que permitan hacer más objetivo el análisis situacional del negocio y la toma de decisiones para el desarrollo de estrategias y planes de acción.

3. Mantenerse permanentemente actualizado, un paso adelante en el cambio de tendencias y en la forma de resolver problemáticas, pero ser consciente que más allá de las capacidades técnicas, las habilidades personales siguen haciendo la verdadera diferencia en los profesionales preferidos por las empresas. 


\section{BIBLIOGRAFÍA}

A lo largo de mi vida profesional muchos textos me han acompañado, cito algunos de ellos:

- La Estrategia del océano azul. Kim, Mauborge

- Lean Enterprise. Humble, O'Reilly

- El método Lean Startup. Erick Ries.

- La Guerra de la mercadotecnia. Ries, Trout

- El nuevo posicionamiento. Trout, Rivkin

- La ciencia del caos. Kotler

- Los 10 pecados capitales del marketing, Kotler

- Las 22 leyes inmutables del marketing, Ries Trout 


\section{ANEXOS}

\section{ANEXO 1: Evidencia de trabajo profesional}

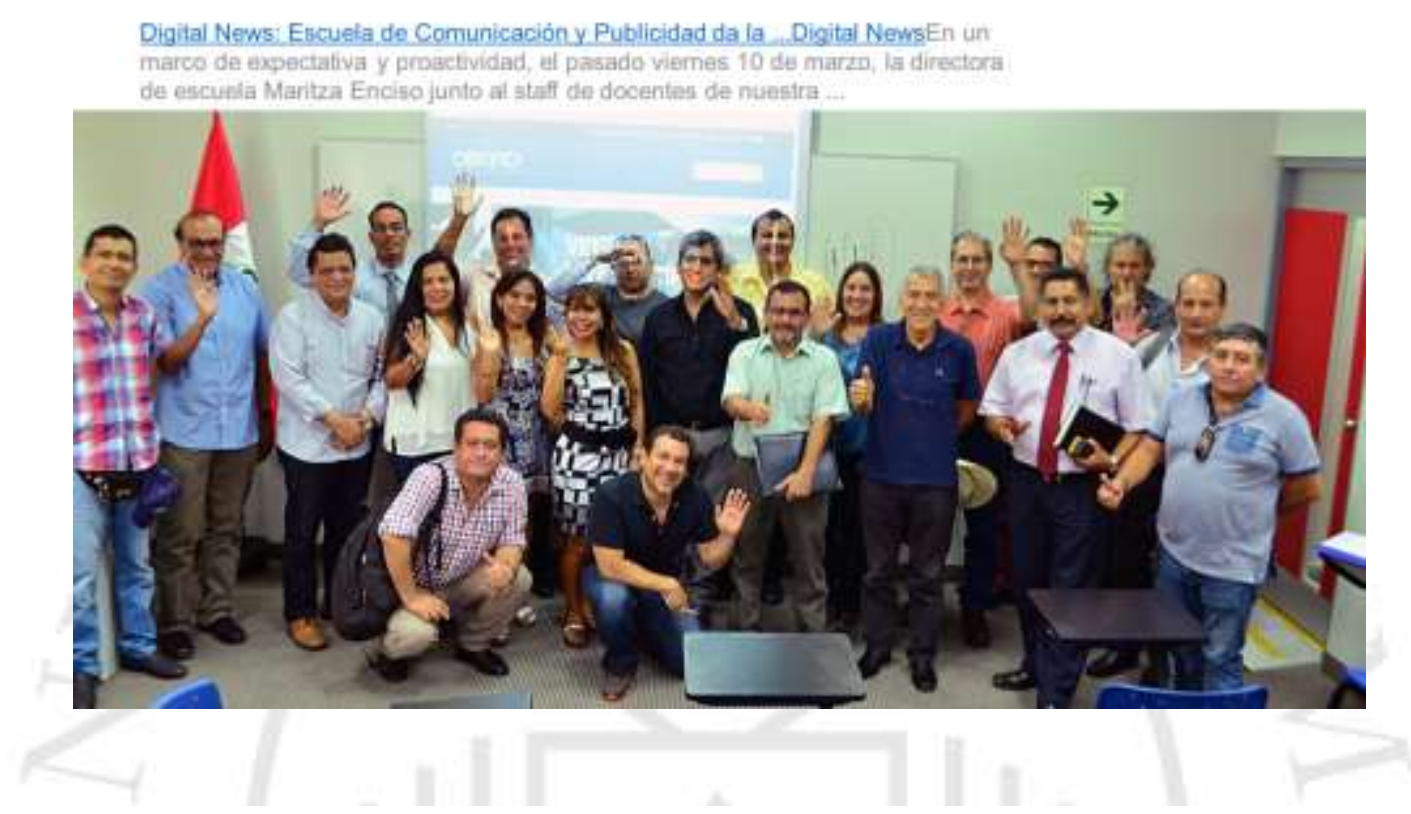

Digital NewS: ACTIVIDADES UCSURDigital News... de primeros ciclos, se realizó el conversatorio

"Corresponsales de Guerra", en la Escuela de Comunicaciones de la Universidad Cientifica del Sur.

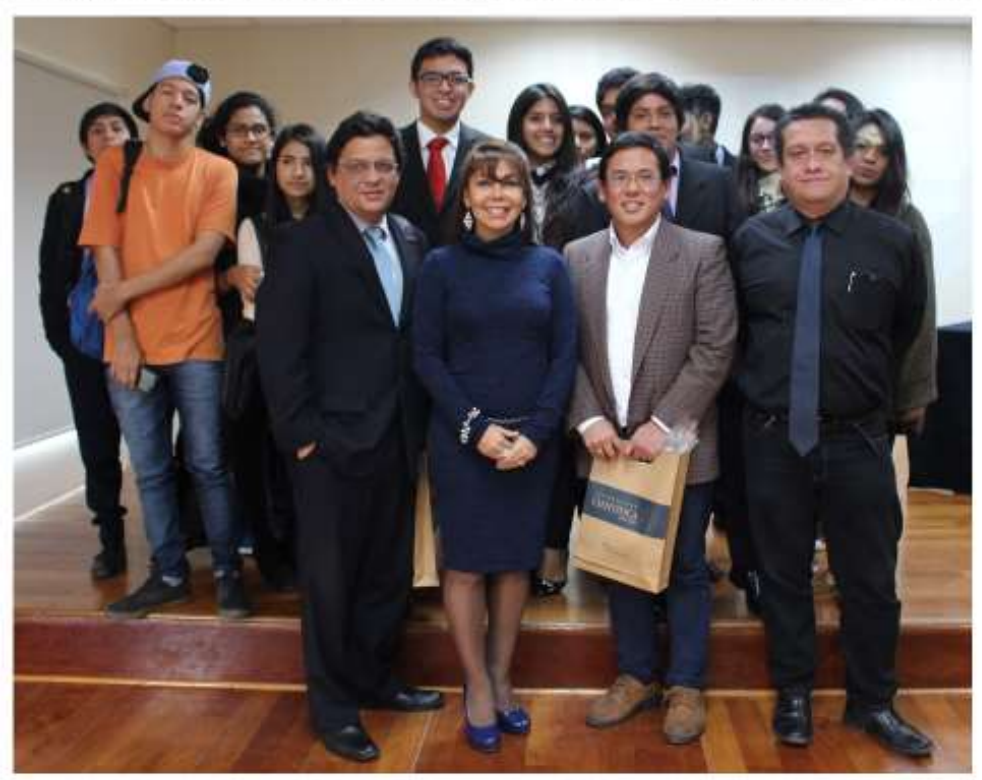


Anuncio de actualización y campo de planes de estudio y creación de mallas curriculares en la creación de las 4 nuevas especialidades dentro de la escuela de comunicaciones

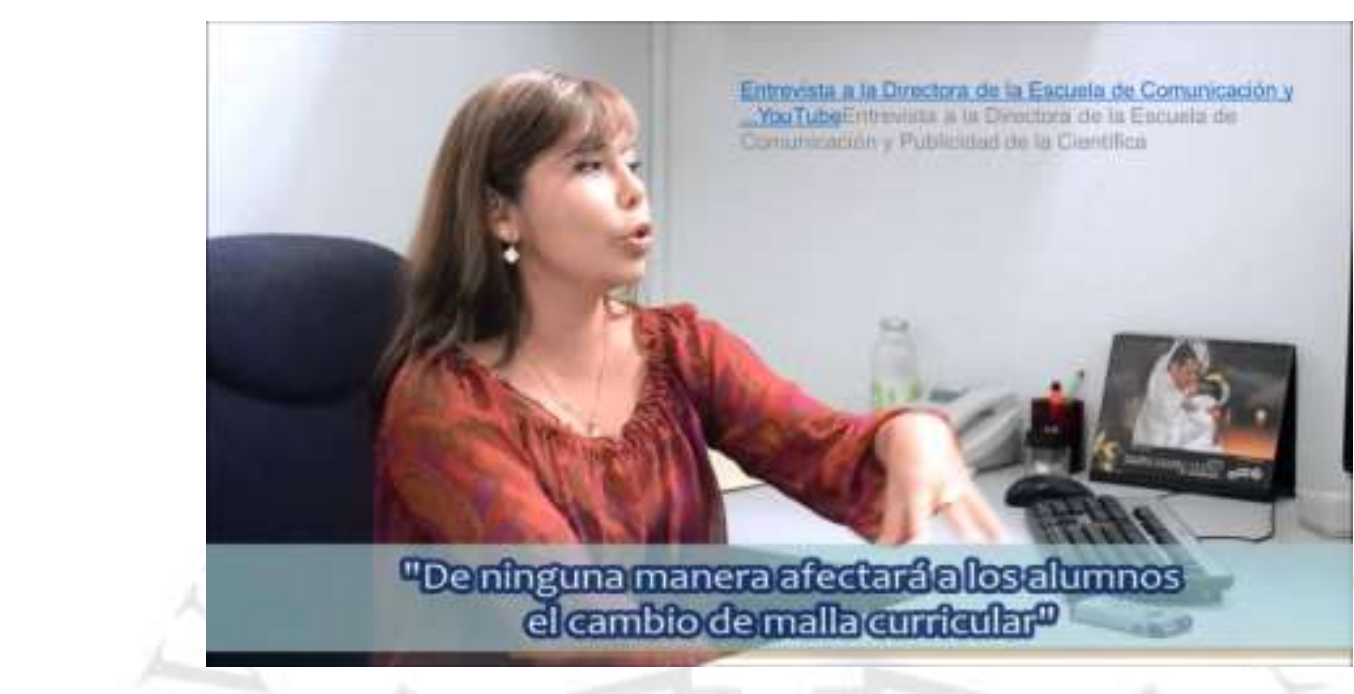

PRESENTACION LANZAMIENTO DE INICIO DE CICLOS ACADEMICOS DE LA ESCUELA DE COMUNICACIONES UCSUR

Escuela de Comunicaciones presenta novedades para este semestre Universidad Cientifica del SurMaritza Eniciso Zegarra, directo realizó la presentación de la Escuela de Comunicaciones 2016-1
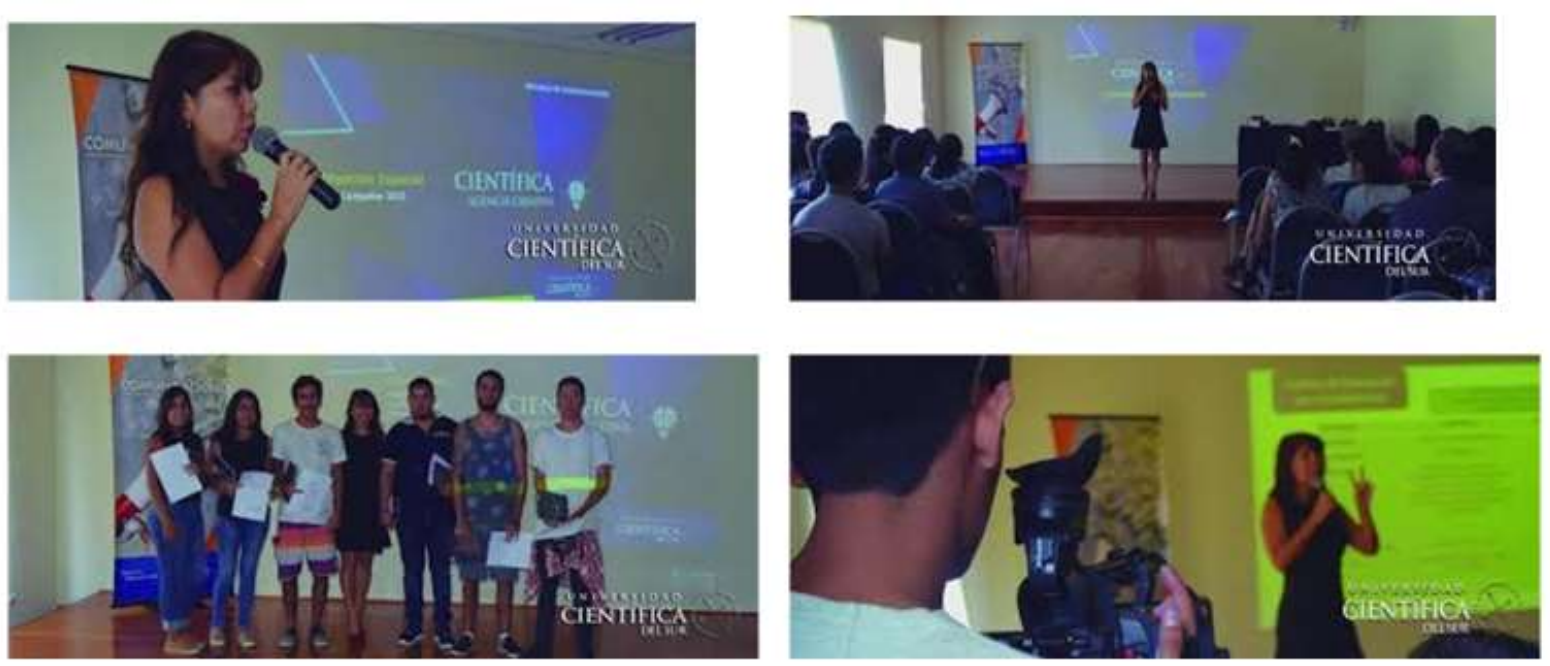

Evidencia (En video). Creación de programas CIENTIFICA RADIO

Evidencia (En video). Reconstrucción de la propuesta de valor. Entrevista

Evidencia (impresa). Revista CIENTIFICA MAGAZINE 